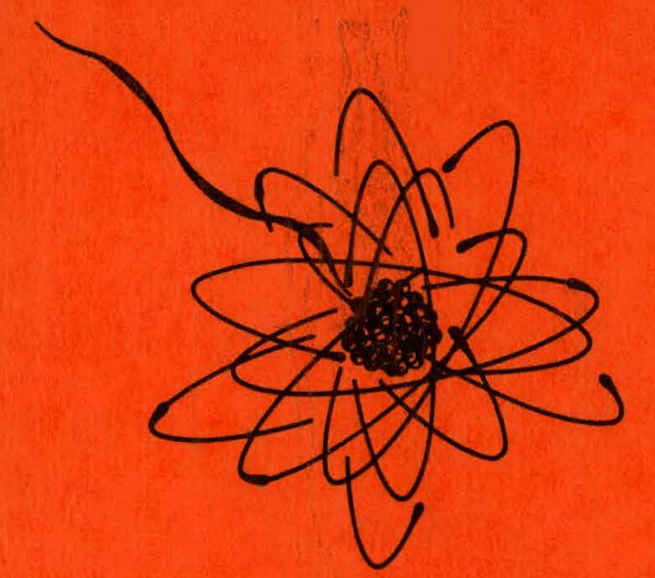

\title{
MASTER YAEC-90
}

YANKEE ATOMIC ELECTRIC COMPANY

RESEARCH AND DEVELOPMENT PROGRAM

A STUDY OF DECONTAMINATION AGENTS

FOR USE IN THE YANKEE REACTOR

R \& D SUBCONTRACT NO.I under

USAEC-YAEC CONTRACT AT (30-3)-222

NOVEMBER, 1958

WESTINGHOUSE ELECTRIC CORPORATION ATOMIC POWER DEPARTMENT

PITTSBURGH,30

P. $0.80 \times 355$

PENNSYLVANIA

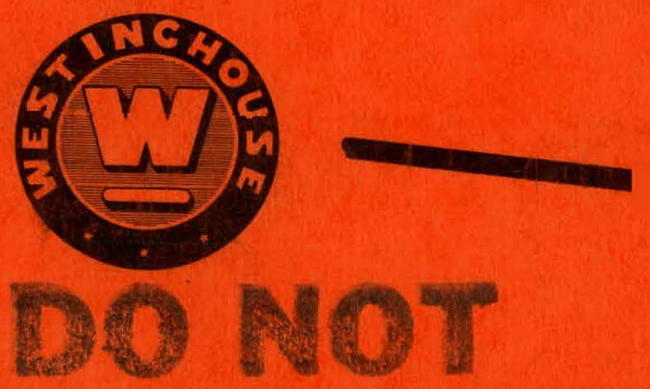




\section{DISCLAIMER}

This report was prepared as an account of work sponsored by an agency of the United States Government. Neither the United States Government nor any agency Thereof, nor any of their employees, makes any warranty, express or implied, or assumes any legal liability or responsibility for the accuracy, completeness, or usefulness of any information, apparatus, product, or process disclosed, or represents that its use would not infringe privately owned rights. Reference herein to any specific commercial product, process, or service by trade name, trademark, manufacturer, or otherwise does not necessarily constitute or imply its endorsement, recommendation, or favoring by the United States Government or any agency thereof. The views and opinions of authors expressed herein do not necessarily state or reflect those of the United States Government or any agency thereof. 


\section{DISCLAIMER}

Portions of this document may be illegible in electronic image products. Images are produced from the best available original document. 


\section{EXTERNAL :DISTRIBUTION}

USAEC, New York Operations Office - 70 Columbus Aive., New York 23, N. Y. 4

USAEC, Division of Reactor Development - $1717 \mathrm{H} \mathrm{St.,} \mathrm{Washington} \mathrm{25,} \mathrm{D.} \mathrm{C.} 8$

USAEC, Commissioner, Patent Branch - Washington 25, D. C. ${ }^{\cdots} \quad$.

USAEC, Technical Information Service Extension - P. 0. Box 62, Oak Ridge, Tennessee

Yankee Atomic Electric Company - 441 Stuart Street, Boston 16, Massachusetts

Yankee Atomic Electric Company - c/o Westinghouse Atomic Power Department, Pittshurgh 30, Pennsylvania (Representative at (D) APD - W. J. Milier) 1

TOTAL

\section{WESTINGHOUSE DISTRIBUTION}

R. I. Wells - W. E. Shoupp

H. C. Amtsberg - P. W. Davison

A. E. Voysey

H. E. Walchli

H. L. Russo

H. W. P. Stanhope

P. B. Haga

C. F. Obermesser

H. A. Smith

T. Stern

R. L. Stoker

W. L. Budge

S. M. Marshall

Technical Information Center
1

1

1

4

1

1

1

1

1

1

1

1

1

2
A. R. Jones

E. T. Morris - M. A. Schultz

W. E. Abbott

G. M. Inman

P. W. Davison

A. G. Thorp II

H. W. Graves

W. H. Arnold

G. H. Minton

J. F. Chalupa

R. K. McGeary

R. F。 Sterling

R. H. Hartley - New York

H. P. Turner - Boston
2

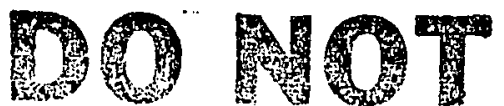

TOTAL

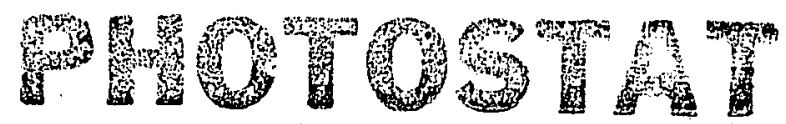


Yankee Atomic Electric Company

Research And Development Program

A STUDY OF DECONTAMINATION AGENTS FOR USE IN

THE YANKEE REACTOR

by

R. M. Watkins

Nuclear Core Engineering

For The Yankee Atomic Electric Company

Under Research and Development Subcontract

No. 1 of USAEC-YAEC Contract AT (30-3)-222

Novernber, 1958

WARRANTY

The Wcetinghouse Electrlc Corporation, Government Agencles, Prime Contractors, Sub-Contractors, or thelr Rspresentatives or other agencies make no representat lon or warranty as to the accuracy or usefulnese of the Information or statements contained is this report, or that the use of any tuformation, apparstus, method or procesa dlaclosod in this report onay not infrigge privately-owned rights. No asgumption of Lubluty 19 assumed with raspect to the use of, or for damages result.Ing Irom the use of, any Information, apparatus, method or procese disclosed in this report.

\section{Westinghouse \\ ELECTRIC CORPORATION \\ ATOMIC POWER DEPARTMENT \\ P.O. BOX 388 \\ PIPTSBURGH 30, PA.}


Page

List of Figures . 3

List of Tables $\cdot 4$

I. Abstract 5

II. Introduction and Statement of the Problem 6

III. Conclusions ㄱ. 7

IV. Survey of Available Decontaminatịon Information 8

V. Experimental Program . 12

A. Bench Screening Tests . 12

B. Detailed Testing of Selected Procedure. 19

VI. Basic Permanganate and Caustic Embrittlement $\quad 26$

A. Iiterature Survey 26

B. Laboratory Evaluation 32

VII. Future Outlook $\quad 32$

VIII. Acknowledgement 4 , 41

IX. Bibliography 42 
1. Stainless Steel Specimen Tested With $3 \% \mathrm{HF}-20 \% \mathrm{HNO}_{3}$ Decontamination Solution

2 Stainless Steel Specimen Tested According to the Chromous SulfateSulfuric Acid Decontamination Procedure

3 Stainless Steel Specimen Tested According to the Basic PermanganateCitrate Decontamination Method.

4 Relation of Exposure Time to Weight Loss in Basic PermanganateCitrate Decontamination of AISI 304 Stainless Steel

5 Relation of Exposure Time to Weight Loss for AISI 304 Stainless Steel in Contact with $10 \%$ Amonium Citrate Solution at $100^{\circ} \mathrm{C}$

6 Relation of Exposure Time to Change in. Surface Finish During Basic Permanganate-Citrate Decontamination of AISI 304 Stainless Steel

7 Stainless Steel Specimen After 88 Hours Exposure to the Basic Permanganate Reagent

8 Stainless Steel Wire Mesh Coils Used as Test Specimens in Decontamination Studies

9 Yankee Fuel Rod Section Cleaned by Exposure to the Basic Permanganate-Citrate Decontamination Reagents

10 Photomicrographs of Stressed Boiler Steel Subject to Corrosion by Alkaline Solution

II Effects of Temperature and Concentration on Cracking of Mild Steel in Sodium Hydroxide

12 Caustic Danger Zone Resulting From the Use of Caustic Solutions on Mild Steel Specimens as Reported by Berk and Waldeck

13 AISI 304 Stainlcoc Ste日l Fatigne Test, Results

14 Fatigue Test Specimens After Failure

15 Bend Area Surfaces of AISI 304 Stainless Steel Cold Bend Test Specimens

16 Cold Berd Test Specimens of $\Lambda$ ISI 304 Stainless Steel Showing Sections Removed for Metallographic Analysis

17 Photomicrographs of Edge of AISI 304 Stainless Steel Cold Bend Test Specimen Pretreated With Basic Permanganate Decontamination Reagent

18 Photomicrographs of AISI 304 Stainless Steel Cold Bend Test Specimen Pretreated with 70\% $\mathrm{NaOH}$.

19 Photomicrographs of AISI 304 Stainless Steel Cold Bend l'est Specimen Unexposed to Basic Permanganate Reagent 
I Decontamination Solutions Suggested for PWR Appiication

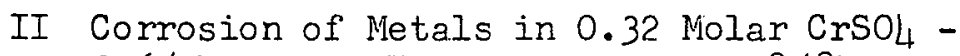
$0.65 \mathrm{Molar}$ of $\mathrm{H}_{2} \mathrm{SO}_{4}$ solution at $85^{\circ} \mathrm{C}$

III United States Steel Corporation Stainless Steel Descaling Procecure

IV Basic Permanganate-Citrate Decontamination Procedure

V Corrosion of Yankee Reactor Primary Coolant System Materials of Construction During Basic Permanganate-Citrate Decontamination 
This report covers a study of chemical decontamination agents for possible use in the Yankee reactor. The necessity for chemical'decontamination is discussed along. with the properties sought in an ideal cleaning solution. A survey of available decontamination information is presented together with a description of the experimental test program carried out at the Westinghouse Atomic Power Department in an effort to develop new" and improved chemical methods for the removal of oxide scale and radioactive contamination from Yankee reactor primary coolant system components. On the basis of bench scale testing of various cleanup procedures, a method employing basic permanganate and citrate solutions has been selected as offering the most promise for successful solution of Yankee primàry loop contamination problems. Data are presented concerning the attack rates produced by these reagents on various reactor materials of construction, as is an evaluation of the possibility of caustic embrittlement of stainless steel resulting from the use of the basic permanganate solution. A discussion of future larger scale testing of the proposed decontaminants is also included. 


\section{INTRODUCTION AND STATEMENT OF THE PROBLEM}

Radioactive contamination of the primary. coolant system of the Yankee reactor will result from fission products (if released from defective fuel elements) and from corrosion products of fuel elements, control rods, and irradiated structural materials. There will be an unavoidable deposition of such materials on interior surfaces of the primary loop system and these may require removal in order to permit acdess for repair and replacement of components. The object of this investigation has been the development of an effective chemical cleanup agent so that this task may be accomplished.

The ideal decontaminating agent should have the ability to remove all of the occluded radioactivity from the deposited oxide layer or crud film. In order to do. this it would be most advantageous if the crud film itself could be dissolved, thus bringing all the contaminants int $b$ solution or suspension. The activity could then be flushed from the system. "It is of course important that the base metal suffer a minimum amount of attack during the decontamination process.

Unfortunately most of the known chemical decontaminating solutions which are strong enough to dissolve the oxide layer are also so dowerful that they may seriously damage the system components, whereas those decontaminants which are safe to use in contact with the materials of construction of the system are usually not strong enough to dissolve the crud film. Thus, the problem resolves itself into the development of a chemical cleanup method which is at the same time both safe to employ and effective in achieving the desired decontamination results. 


\section{CONCLUSION}

On the basis of bench tests of available cleanup procedures a method employing basic permanganate and citrate solutions has been selected for use in larger scale studies, as it apparently. offers the móst promise for successful Yankee reactor application. When properly applied, this procedure could provide a safe and efficient method of descaling the stainless steel primary coolant piping without causing serious damage to other materials in the system. The deposited crud film is dissolved by the treatment, thus bringing the activity within it into solution or suspension. The results of the bench scale tests have indicated that an overall decontamination factor of at least 10 (i.e., $90 \%$ activity removal) can be achieved through the use of this procedure.

It was concluded on the basis of results from fatigue tests, cold bend tests, and metallographic examinations, that no embrittlement problem exists as a result of the use of the basic permanganate reagent and that it may be safely employed in cleaning austenitic stainless steel without significant danger of caustic cracking of the metal. 


\section{SURVEY OF AVAILABLE DECONTAMINATION INFORMATION}

Prior to undertaking an experimental program of screening tests of cleanup agents for possible use in the Yankee reactor, a survey of available decontamination information was conoucted. One of the earliest documents examined was a comprehensive report concerning decontamination of stainless steel which was written at Oak Ridge National Laboratory by D. O. Campbell in March, 1955.1 The most effective "non-corrosive" decontaminant suggested. at that time was an alkaline tartrate peroxide solution. After the initial application of this reagent, its action is improved by a subsequent treatment of the contaminated surface with nitric acic. Several alternate treatments with nitric acid and alkaline tartrate-peroxide gave the best decontamination wi.th negligible corrosion, however, these reagents are unable to dissolve the deposited oxide film, and only leach some of the activity from it with each successive application.

The most effective decontaminant reported was a. $3 \%$ hydrofluoric acid - $20 \%$ nitric acid solution. This reagent has the ability to dissolve the oxide layer which forms on stainless steel when it is exposed to high temperature pressurized water during reactor operation, but it is found to severely corrode the base metal. The rate of decontamination is reported for sodium hydroxide, alkaline tartrate, alkaline tartrate-peroxide, nitric acid, and oxalic acid. These reagents are found to decontaminate rapidly at first, but the rate of activity removal drops off rapidly with time. As of 1955 apparently no reagent was known which had the ability to completely dissolve a crud layer without seriously damaging the base metal.

In October, 19,56 a report was issued by the Hanford Atomic Products Operation, Richland, Washington, which gives additional information as to the corrosion rates to be expected should AISI 30LL stainless steel be exposed to solutions of $20 \%$ nitric acid - $20 \%$ sodium dichromate, or $20 \%$ nitric - 3\% hydrofluoric acid.? The results indicate that sensitized specimens of this particular austenitic stainless steel would be subject to corrosion rates of as high as 0.2 to 1.0 inches per year as a result of the application of these reagents. The report concludes that "both solutions are extremely corrosive". Certainly such treatments could not be used safely in the decontamination of components where close tolerances must be maintained.

In an attempt to protect materials of construction from undue attack, many mild cleaning agents have recently been proposed for use in removing radioactivity from crud covered components. One of the best known of these procedures is that developed at the Bettis Plant for the Shippingport Pressurized Water Keactor. 3, 4, 5, 6 'l'he suggested decontaminant for use on crud deposits is an aqueous solution in the $\mathrm{pH}$ range of 1.5 to 2.2 containing a $\mathrm{pH}$ adjusting reagent, a complexing or chelating reagent with corrosion inhibitor, and a reducing agent such as hydrazine or hypophosphite. Should the cleanup operation involve the removal of $\mathrm{UO}_{2}$ and fission product contamination, an oxidizing agent such as hydrogen peroxide plus a stabilizer would be required. A typical list of the solution ingredients with their suggested concentrations is given in Table $I$. 


\section{TABLE I}

Decontamination Solutions Suggested

For PWR Application 4,5,6

\begin{tabular}{|l|c|c|c|}
\hline \multirow{2}{*}{ Ingredients } & \multicolumn{3}{|c|}{ Description } \\
\cline { 2 - 5 } & $\begin{array}{c}\text { Dilute } \\
\text { Oxidizing }\end{array}$ & $\begin{array}{c}\text { Concentrated } \\
\text { Oxidizing }\end{array}$ & $\begin{array}{c}\text { Concentrated } \\
\text { Reducing }\end{array}$ \\
\hline Hydrogen Peroxide (g/L) & 0.3 & 1.5 & \\
Acetanilide $(\mathrm{g} / \mathrm{L})$ & 0.1 & 0.5 & 5 \\
Hydrazine (g/L) & 0.15 & 0.75 & 3.5 \\
Ethylenediamine Tetracetic & $0.25-0.5$ & 2.5 & 25. \\
Acid (g/L) & 0.1 & 0.5 & 1. \\
Sulfamic Acid (g/L) & $250 \% \mathrm{~F}-300 \%$ & $250 \%-300 \%$ & $200 \%-250 \%$ \\
Hexamethylenetetramine $(\mathrm{g} / \mathrm{L})$ & $1.8-2.3$ & -1.5 & -1.5 \\
Temperature & & & \\
pH & &
\end{tabular}


Although the reducing solutions suggested by the Bettis Plant report do not completely dissolve the oxide film, they may loosen it to an extent where violent agitation results in the flaking off of a large portion of the oxide scale which can then be flushed away. However, it is difficult to achieve the needed agitation throughout the entire system; thus though this procedure is noninjurious to the base metal, the contaminating activity may not be removed to the desired extent. A summary of results achieved by the use of these solutions in decontamination trials that had been reported up to January, 1958 is contained in a "Li.terature Survey for Activity Build-Up on Reactor Primary System Components", edited by A. L. Medin anc issued by. Alco Products, Inc., of Schenectady, New York.?

Although the Bettis Plant procedure for the decontamination of primary coolant systems has been reported ${ }^{8}$ as being favorably considered for naval reactor and PWR application, a study has been made by $R$. D. Baybarz at Oak Ridge. National Laboratory of an improved cleanup method for use in the Homogeneous Reactor Experiment. The new procedure developed by Baybarz involves the use of a 0.40 molar chromous sulfate -0.5 molar sulfuric acid solution at 80 to $90^{\circ} \mathrm{C}$ for 2 to 4 hours in order to dissolve the oxide film. ${ }^{9}$ This is a very powerful reducing agent and must be used in an inert atmosphere in order to prevent a reaction with atmoshperic oxygen.

The above procedure has been employed with satisfactory results in $\mathrm{UO}_{2} \mathrm{SO}_{4}$ dynamic loop cleanup operations, and has produced decontamination factors on contaminated stainless steel which were superior to those achieved with the milder reducing agents as developed at the Bettis Plant.9,7 Typical corrosion results obtained from the use of the chromous sulfate-sulfuric acid procedure on reactor primary system construction materials are given in Table II. Although most of the corrosion results listed in the table suggest that there was only very slight attack, the depth of penetration reported for AISI 304 stainless steel indicates that the chromous sulfate reagent is still potentially dangerous to a system containing sensitive elements fabricated of such a material.

Work with inhibited acid and detergent cleanup solution has been performed at the decontamination facility operated by the Fairchild Camera and Instrument Corporation of. Syosset, Iong Island, New York. WEDAK, a detergent containing highly inhibited phosphoric acid which is manufactured by the. West Disinfectant Company of Iong Island City, New York has been usedlO quite successfully to decontaminate control rod drive mechanisms received for cleanup under contract with the Knolls Atomic Power Laboratory. Brush scmibbing is used in conjunction with exposure to the cleanup reagent in order to achieve the desired decontamination results. 11

In contrast with the acid detergent treatment in use at the Fairchild Decontamination Facility, and the acid reducing agent procedures recommended for crud removal by the Bettis Plant and the Oak Ridge National Laboratory, the United States Steel Corporation suggests a method for oxide scale removal from stainless steel which employes a strong oxidizing agent similar to those studied at the Hanford Atomic Products Operation. 12,2 In this case however

$$
-10-\quad 378 \quad 0.10
$$


TABLE II

Corrosion of Metals in 0.32 Molar Solution of $\mathrm{CrSO}_{4}-0.65$ Molar Solution of $\mathrm{H}_{2} \mathrm{SO}_{4}$ at $85^{\circ} \mathrm{C}^{9}$

(4.4. hr. contact time in dynamic loop)

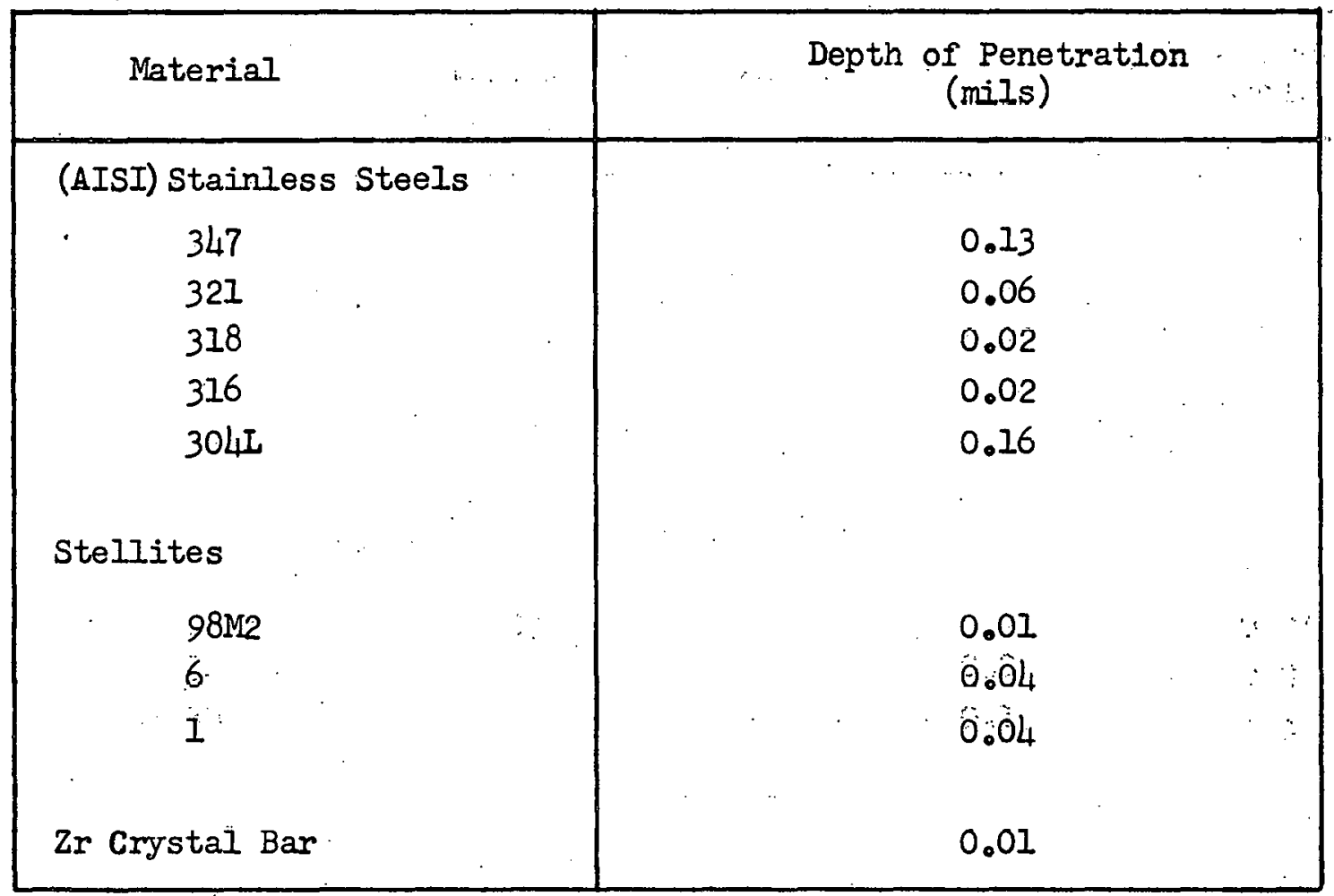


a strong caustic environment is maintained during the first stage of the cleanup operation, and this is followed by a nitric acid wash. Table III indicates the actual chemical ingredients of the solutions employed in this procedure together with their suggested concentrations.

The use of ultrasonic energy for use in decontamination in conjunction with chemical procedures should also be mentioned. As early as 1955 extensive work was in progress both at the Hanford Atomic Products Operation 13 and the Oak Ridge National Laboratoryl concerning the application of ultrasonic equipment in the problem of reactor system decontamination. It was felt that the use of ultrasonics together with solutions less corrosive than nitric acid might provide better decontamination than had yet been achieved. High-intensity ultrasonic radiation was found to increase the rate of decontamination, but the problem of introducing ultrasonic radiation into large equipment was recognized as a formidable one. Work along this line is presently continuing at the General Electric Company, Schenectady, New York, where a recent study has been made to determine whether ultrasonic vibration would be effective in removing mixed radipactive deposits from the inside surface of steel pipes in a heat exchanger. 14 It was found, as expected, that the effectiveness of the ultrasonic energy in enhancing the decontamination effect depends rather critically on the method of coupling to the work. Apparently the solution to the problem of perfecting practical ultrasonic decontamination still depends on the development of an efficient method for the introduction of the ultrasonic energy into the chambers to be cleaned.

\section{EXPERIMENTAL PROGRAM}

A. BENCH SCREENING TESTS

After examining the available decontamination information, a series of bench screening tests was performed in order to evaluate the effectiveness of various cleaning reagents in dissolving the type of film to be found on intermal. surfaces exposed to primary coolant in the Yankee reactor. Crud coated sample coupons of various materials to be used in the fabrication of the Yankee primary system components were prepared in dynamic loops under water chemistry conditions closely approaching those to be found during reactor operation. 15

Clean sensitized specimens of AISI 304 stainless steel and other construction materials were also used in tests to determine the extent of the attack on base materials. As no radioactive specimens were available for these cle anup tests, all estimates as to the effectiveness of the solutions tested were made from weight loss data and on the basis of visual observations. 


\section{TABLE III}

United States Steel Corporation Stainless Steel.

\section{Descaling Procedure 12}

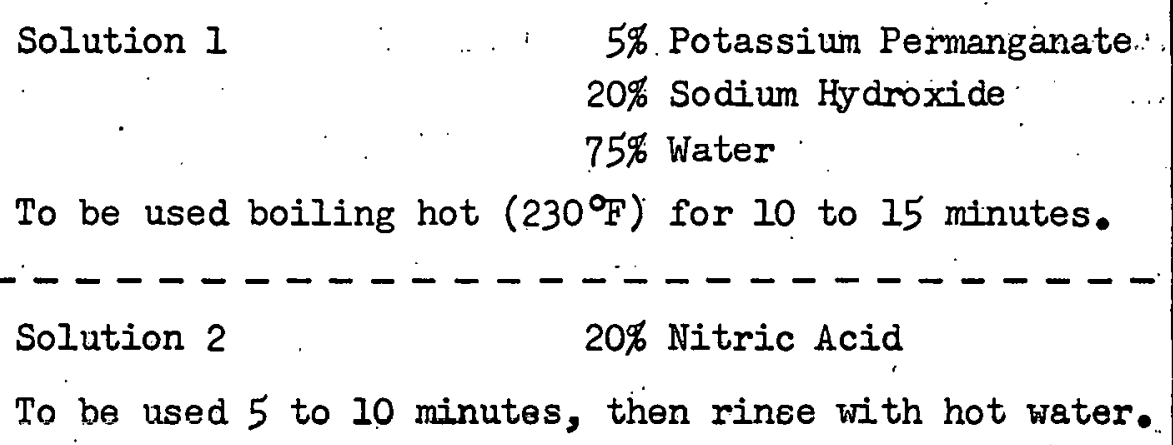


The alkaline tartrate-peroxide solution and the three Bettis Plant solutions outlined in Table I were found to be ineffective in static attempts at dissolving Yankee type oxide films. Without violent agitation these solutions are apparently incapable of dissolving or even loosening such an oxide scale.

Tests using 3\% hydrofluoric acid - 20\% nitric acid solution effected removal of the deposited oxide film from stainless steel surfaces as expected, but resulted in very serious attack on the base metal (see Figure 1)。

Experimentation with the chromous sulfate-sulfuric acid procedure as developed at the Oak Ridge National Laboratory9 yielded improved results, as the oxide layer could be dissolved with less severe attack on the base metal, accompanying the cleaning operation. However, the reagent was difficult to prepare and apply since it reacts with oxygen, and there were still definite signs of intergranular attack visible in an examination of treated metal surfaces (see Figure 2). Tests conducted with WEDAK solution 10 according to the procedure used by the Fairchild Camera and Instrument Corporation indicated that this reagent is capable of dissolving Yankee type oxide films, but that undue attack on stainless steel could still result if prolonged contact were allowed. Though this method appeared promising it was felt that a more adequate procedure could be found.

The results of cleanup tests using the basic permanganate-nitric acid procedure suggested by the United States Steel Corporation 12 proved most satisfactory. It was found that the oxide film could be dissolved completely without any significant attack on the stainless steel base metal. However, the danger remained that less corrosion resistant materials which might be present in the reactor system could be seriously damaged by the $20 \%$ nitric acid rinse solution.

In view of the potential hazard introduced by the use of nitric acid, a system substituting the use of a complexing agent (ammonium citrate) for the acid rinse was tested. This "Basic Permanganate-Citrate Method" provides an excellent colution to the acid allack problem as it completely avoids the use of strong acid which might be injurious to the system. The procedure employed and chemical ingredients used are given in Table IV.

The cleanup results produced by these reagents on sensitized specimens of AISI 304 stainless steel were found to be excellent. No signs of intergranular attack are evident and weight loss per unit area is negligible. (See Figure 3.)

After a comparison of the cleanup results produced by the various procedures tested, the basic permanganate-citrate method was chosen as the one showing. the most promise for possible application in Yankee reactor decontamination. 


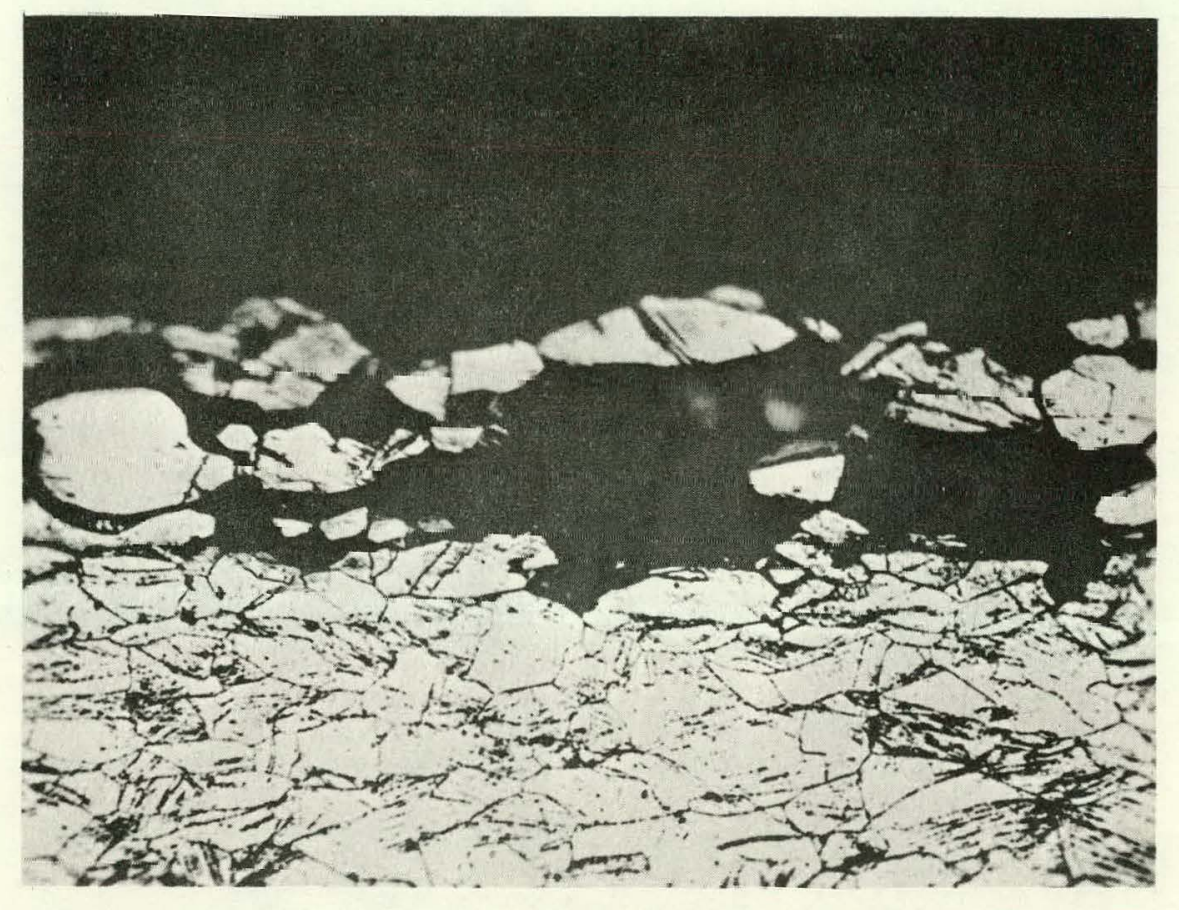

Figure 1 Photomicrograph (400X) of Edge of Sensitized Specimen of AISI 304 Stainless Steel l'ested with 3\% $\mathrm{HF}-20 \% \mathrm{HNO}_{3}$ Decontamination Solution. 


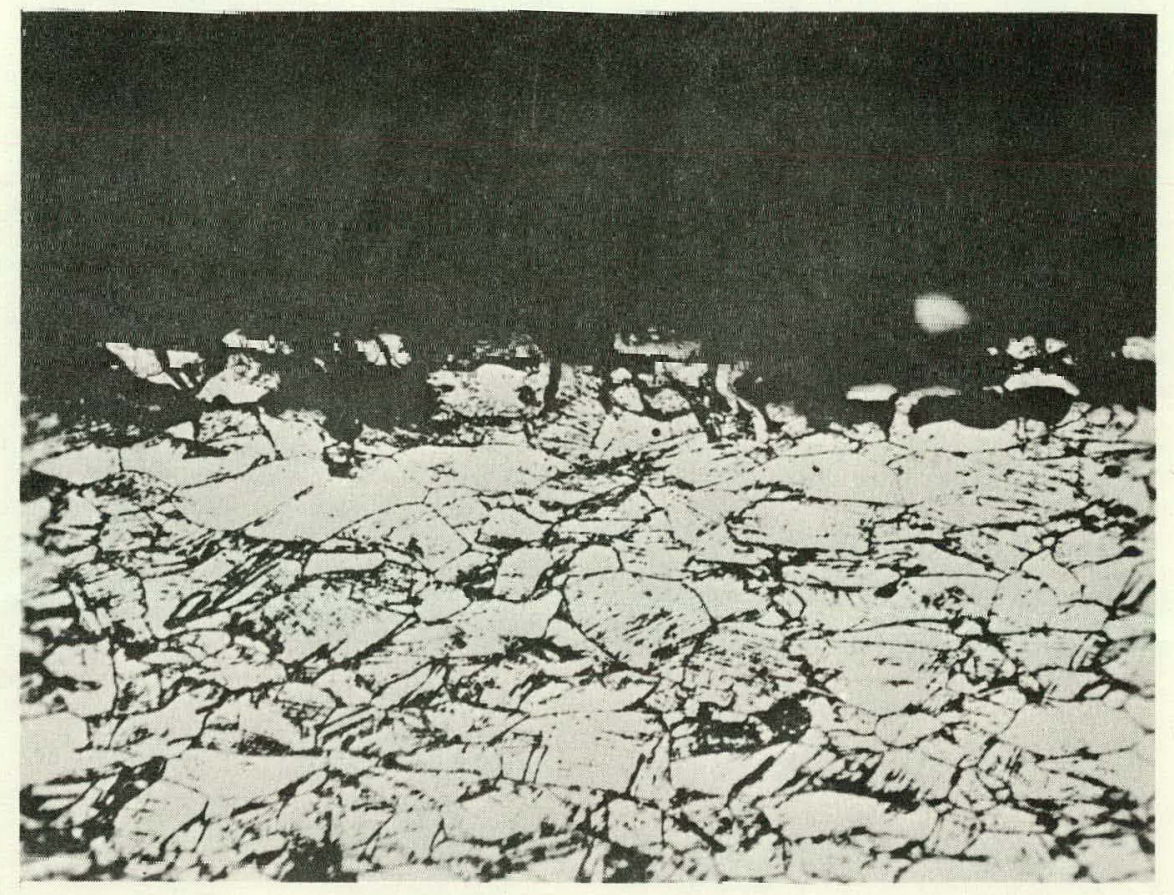

Figure 2 Photomicrograph (400X) of Edge of Sensitized Specimen of AISI 304 Stainless Steel Tested According to the Chromous Sulfate-Sulfuric Acid Decontamination Procedure. 


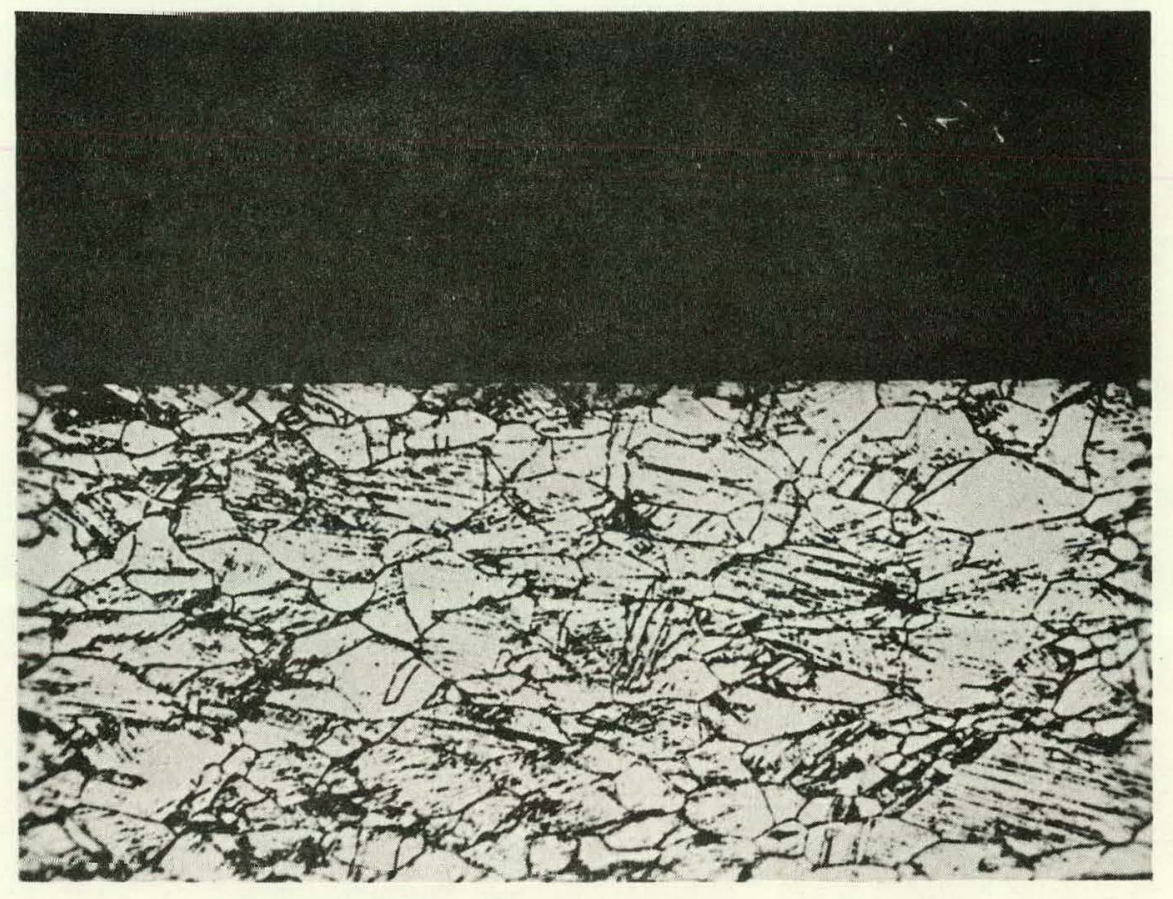

Figure 3 Photomicrograph (400X) of Edge of Sensitized Specimen of AISI 304 Stainless Steel Tested According to the Basic Permanganate-Citrate Decontamination Method. 


\section{TABLE IV}

Basic Permanganate-Citrate Decontamination Procedure

\begin{tabular}{|l|c|c|}
\hline $\begin{array}{c}\text { Chemical Ingredients of } \\
\text { Cleanup Solutions }\end{array}$ & $: \begin{array}{c}\text { Contact Time } \\
\text { Minutes }\end{array}$ & $\begin{array}{c}\text { Temperature } \\
\text { Degrees C }\end{array}$ \\
\hline $\begin{array}{l}18 \text { Percent } \mathrm{NaOH} \\
3 \text { Percent } \mathrm{KMnO}\end{array}$ & 30 & 105 \\
$\begin{array}{l}\text { Hot water Rinse }\left(65-95^{\circ} \mathrm{C}\right), \\
\text { then }\end{array}$ & & 100 \\
2. 10 Percent Ammonium Citrate
\end{tabular}




\section{B. DETAIILED TESTING OF SELECTED PROCEDURE}

An extensive series of tests was conducted using the $3 \% \mathrm{KMnO}_{4}-18 \%$ $\mathrm{NaOH}$ "basic permanganate" solution and the 10\% ammonium citrate reagent under various conditions and in contact with assorted reactor materials. The standard treatment times and temperatures, as cited in Table IV, were used in all tests unless otherwise stated.

The relation of exposure time to weight loss for AISI 304 stainless steel at $105^{\circ} \mathrm{C}$. in the basic permanganate solution is shown in Figure 4. Note that time is shown on a log scale, and that the attack is seen to drop off exponentially with time. As an average penetration of 1/1000 of a mil is equivalent to a weight loss of approximately $2 \mathrm{mg}$ per $\mathrm{dm}^{2}$. for this material, this graph shows that after an exposure of 120 minutes, the average penetration is still less than $3 / 1000$ of a mil.

The relations of exposure time to weight loss for AISI 304 stainless steel in contact with $10 \%$ ammonium citrate solution at $100^{\circ} \mathrm{C}$ is shown in Figure 50. Here again the weight loss drops off rapidly with time. After 54 hours the total attack on the base metal resulting from the use of this solution was still quite negligible.

The relation of exposure time to change in surface finish during basic permanganate decontamination of AISI 304 stainless steel is illustrated in Figure 6. After an initial increase in surface roughness there is very little change during a prolonged exposure. This test was conducted for a total of $3-1 / 2$ days starting with highly polished coupons, the standard 15 minute citrate treatment being used after each exposure to the basic permanganate solution. One of the stainless steel specimens used in the surface finish test after 88 hours of exposure to the basic permanganate solution is shown in Figure 7. It is of interest to note that the reflection of the caption. Is clearly visible on the coupon's surface as it has retained its original polished appearance.

In order to achieve a high ratio of surface area to mass for accurate weight loss determinations AISI 304 stainless steel wire mesh coils were used as test specimens in many of these decontamination studies. Two such samples, one after cleanup and one still coated with an oxide layer formed during exposure in a static autoclave, are shown in Figure 8 .

AnAISI 304 stainless steel clad Yankee fuel rod section exposed for 708 hours to boronated water in a dynamic loop at $600^{\circ} \mathrm{F}$ and $1850 \mathrm{psi}$ is snown in Figure 9. The right half of this rod section was cleaned according to the basic permanganate citrate procedure. It is interesting to note that this method may be considered for use in cleaning individual fuel rods after autoclave leak testing, but prior to brazing into fuel bundles. The light scale formed in the autoclave tests must be removed before the brazing operation. This procedure may offer a simple solution to the problem. 


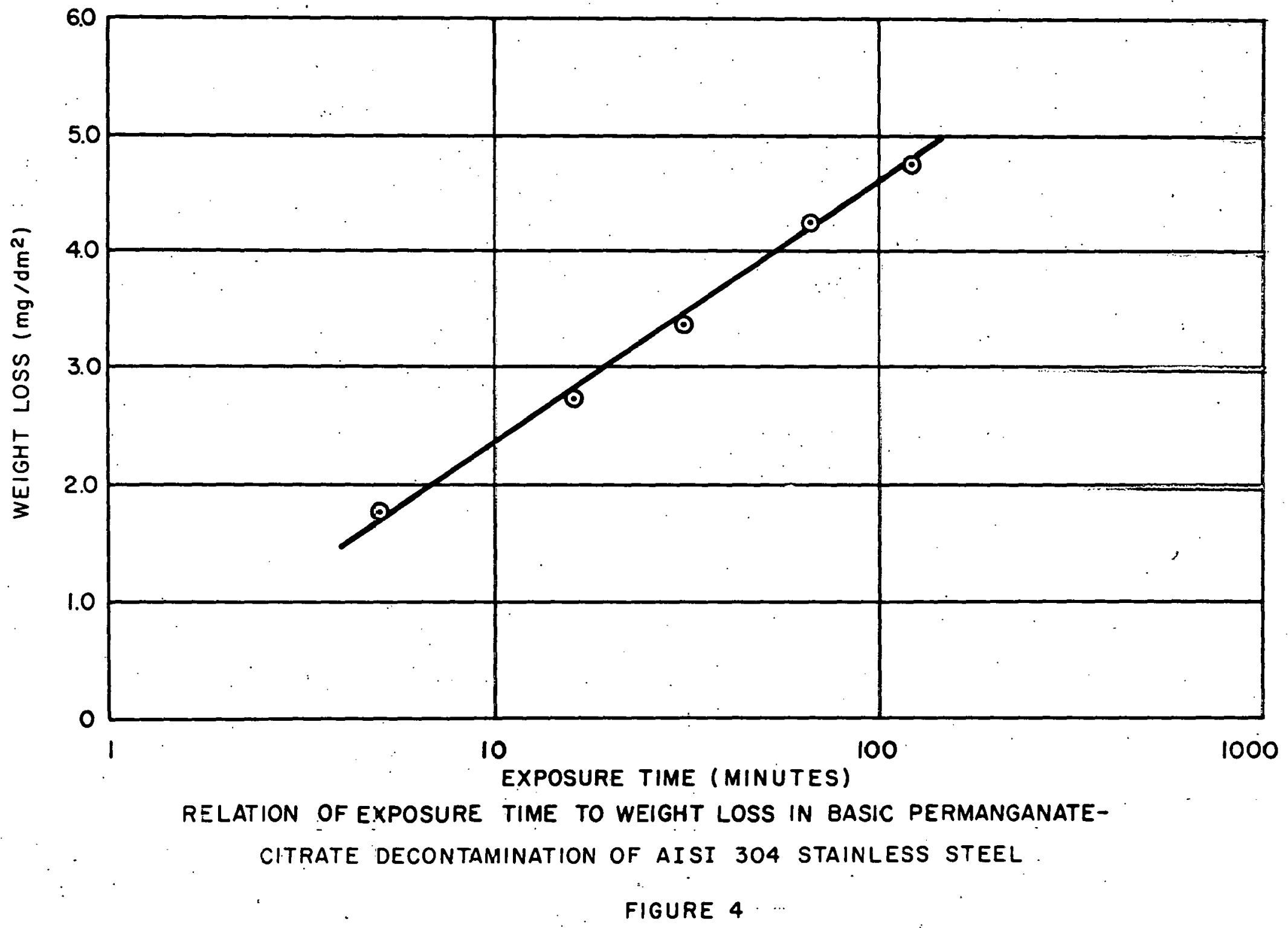




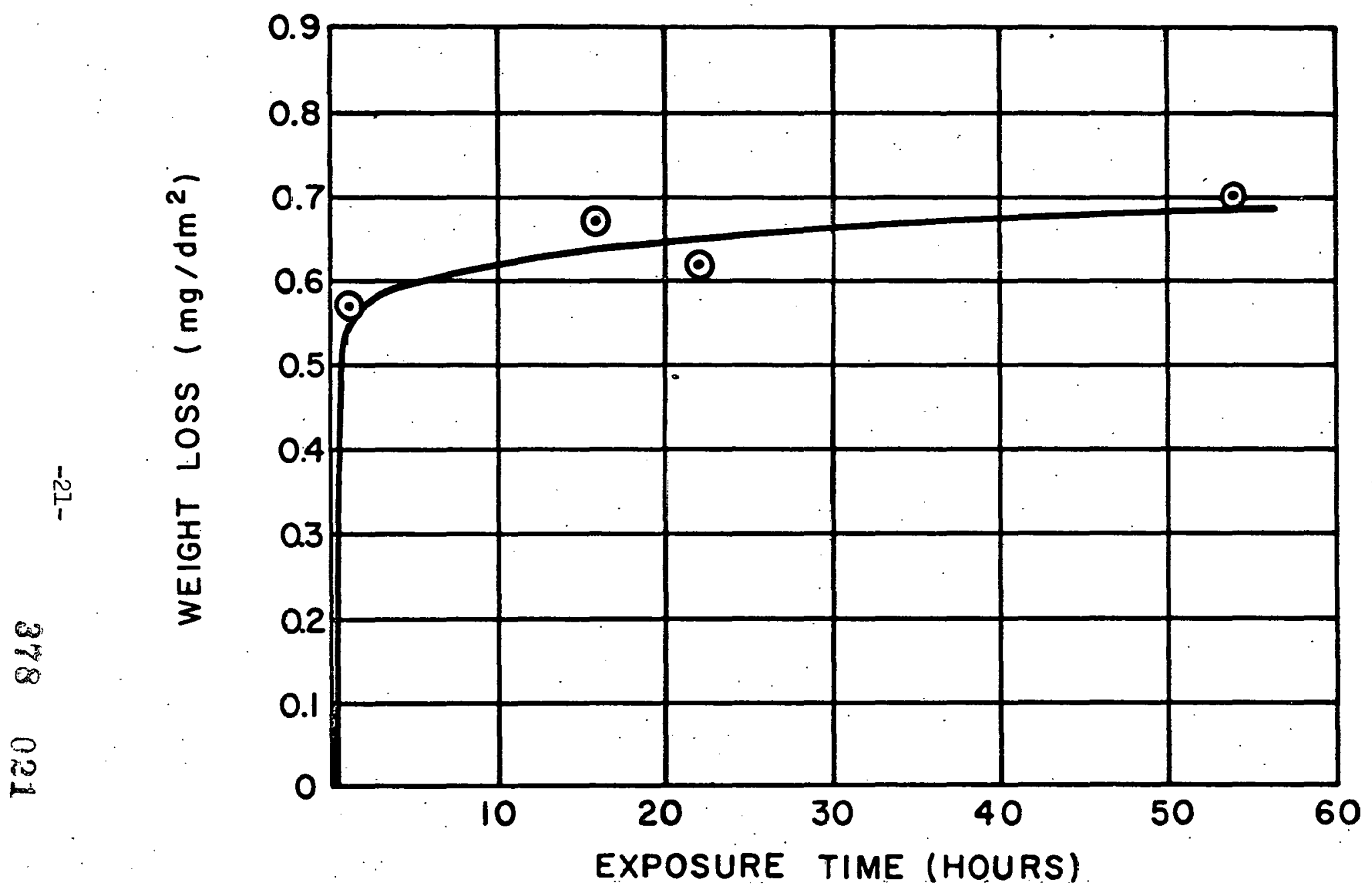

RELATION OF EXPOSURE TIME TO WEIGHT LOSS FOR AISI 304 STAINLESS STEEL IN CONTACT WITH $10 \%$ AMMONIUM CITRATE SOLUTION AT $100^{\circ} \mathrm{C}$ 


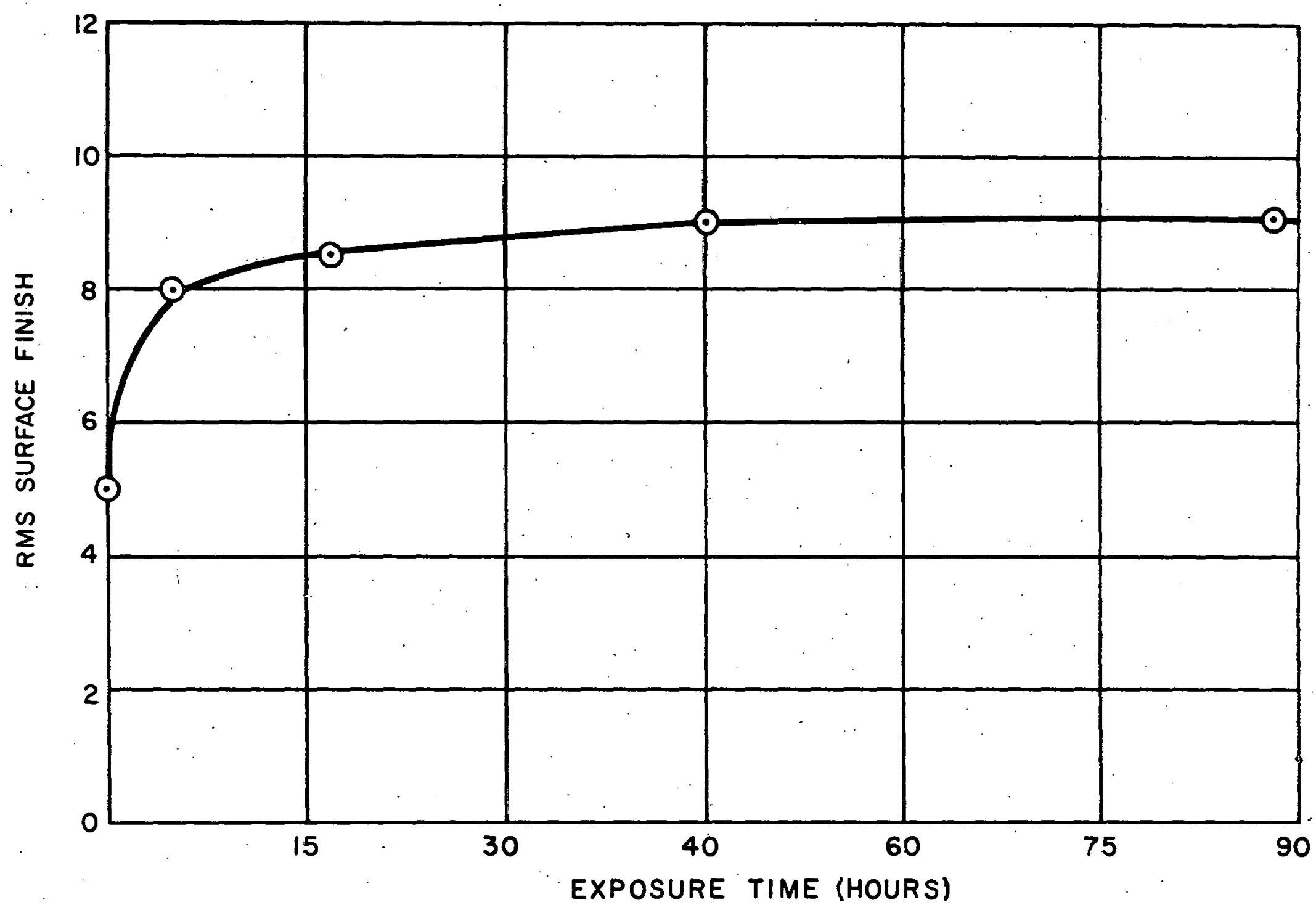

RELATION OF EXPOSURE TIME TO CHANGE IN SURFACE FINISH DURING BASIC PERMANGANATE-CITRATE DECONTAMINATION OF AISI 304 STAINLESS STEEL 


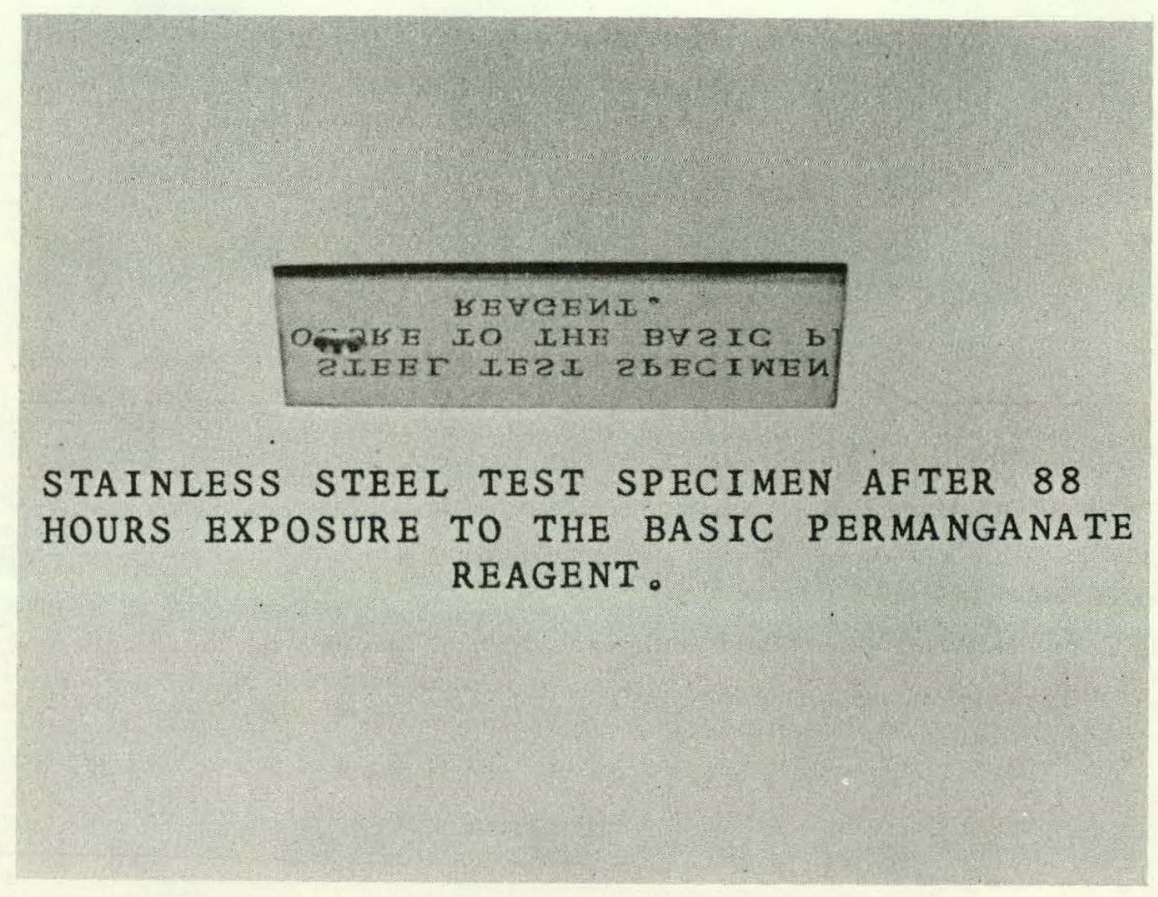

Figure 7 Note Reflection of the Caption on the Test Coupon's Surface Which Has Retained its Original Polished Appearance, 


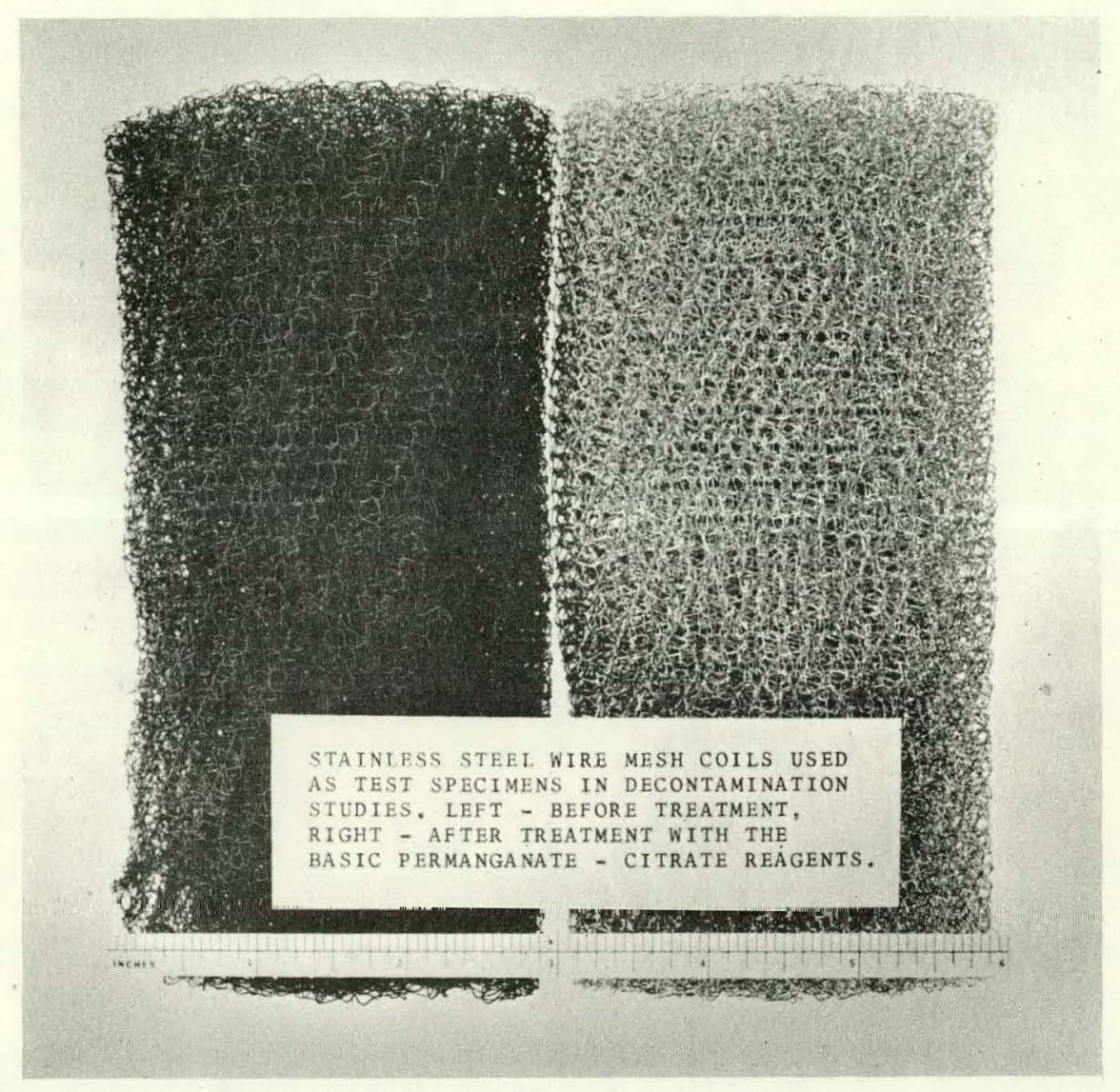

Figure 8 (Each of the Wire Mesh Coils Shown Above Have Surface Areas of Over $33 \mathrm{dm}^{2}$.) 
TYPE 304 STAINLESS STEEL FUEL ROD SECTION EXPOSED FOR 708 HOURS TO BORONATED WATER AT 600 DEGREES F . \& 1850 PSI. RIGHT HALF CLEANED VIA EXPOSURE TO THE BASIC PERMANGANATE CITRATE DECONTAMINATION REAGENTS .

Figure 9 AISI 304 Stainless Steel Yankee Fuel Rod Section Exposed for 708 Hours to Boronated Watcr at $600^{\circ} \mathrm{F}$ and $1850 \mathrm{psi}$. Right Half Cleaned by Exposure to the Basic Permanganate - Citrate Decontamination Reagents. 
The results of corrosion tests performed with a variety of materials proposed for use in the Yankee reactor primary coolant system are summarized in Table $V$. Although the corrosion rates may appear high in some cases, the actual depth of penetration per defilming operation is small since less than an hour is required for complete oxide dissolution and removal. The results of the bench scale tests have indicated that an overall decontamination factor of at least 10 (i.e., 90\% activity removal) can be achieved through the use of this procedure and it is anticipated that much larger D.F. values may be obtained. Quantitative measurement of such values can not be made, however, without the use of radioactive test specimens.

\section{BASIC PERMANGANATE AND CAUSTIC EMBRITTLEMENT}

The most serious objection raised concerning the use of the basic permanganatecitrate decontamination procedure has been the possibility of caustic embrittlement of stainless steel resulting from contact with the hot sodium hydroxide solution which is used as the primary reagent in this procedure. In an effort to determine the possibility of the occurrence of such attack, a literature survey on the subject of caustic embrittlement of steel was concucted and a series of fatigue tests and cold bend tests followed by metallographic analysis was carried out.

\section{A. LITERATURE SURVEY}

The literature search on the subject of caustic embrittlement of steel in general was made by the use of the "Bibliographic Survey of Corrosion" published annually by the National Association of Corrosion Engineers. Particular attention was paid to all references to this phenomena occurring in ferrous alloys containing nickel and chromium. The following abstracts present the most significant information obtained with regard to the problem of possible embrittlement of stainless steel resulting from exposure to the basic permanganate reagent.

Uhlig, in his classical "Corrosion Handbook"16, mentions caustic embrittlement in carbon steel boilers and gives several examples of the occurrence of this phenomenon together with photomicrographs of the intercrystalline cracks which are typical of this type of attack. (See Figure 10.) No mention is made concerning embrittlement of stainless steel. He states, however, that the minimum $\mathrm{NaOH}$ concentration necessary to cause caustic embrittlement in a carbon steel boiler is 10\%. (A long exposure period at high temperature and pressure is assumed in a discussion of boiler corrosion.) 


\section{TABLE V}

Corrosion of Yankee Reactor Primary Coolant System

Materials of Construction During Basic Permanganate-

Gitrate Decontamination

\begin{tabular}{|l|c|c|}
\hline \multicolumn{1}{|c|}{ Material } & $\begin{array}{c}\text { Wt, Loss } \\
\mathrm{mg} / \mathrm{cm}^{2} / / 30 \mathrm{~min}\end{array}$ & $\begin{array}{c}\text { Average Penetration } \\
\text { AIIs }\end{array}$ \\
\hline AISI $304 \mathrm{~s} / \mathrm{s}$ & 0.035 & 0.0017 \\
AISI $316 \mathrm{~s} / \mathrm{s}$ & 0.033 & 0.0016 \\
AISI $347 \mathrm{~s} / \mathrm{s}$ & 0.032 & 0.0016 \\
AISI $410 \mathrm{~s} / \mathrm{s}$ & 0.34 & 0.018 \\
Nicrobraze-50 & 0.56 & 0.032 \\
InconeI & 0.02 & 0.001 \\
80\% Ag-15\% In-5\% Cd & 2.28 & 0.090 \\
ControI Rod AIloy & 0.67 & 0.132 \\
Graphitar-14* & & \\
\hline
\end{tabular}

* A "back flushing" procedure is: suggested for preventing the decontaminants from contacting Graphitar pump bearings during cleanup operations of an: existing loop or reactor: The corrosion values listed for Graphitar could be considerably reduced through the application of such a technique: 

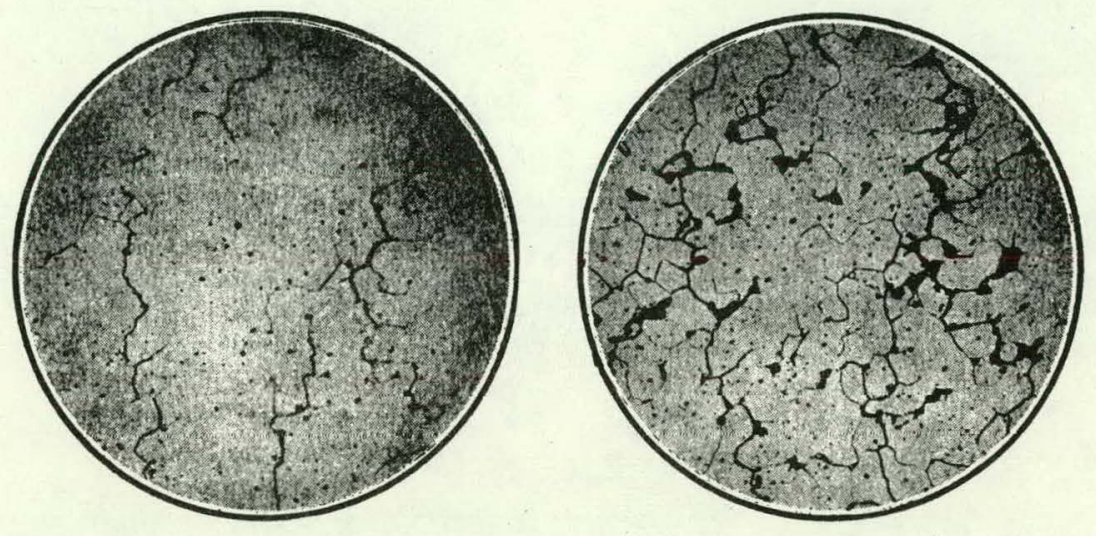

Figure 10 Photomicrographs (200X) of Stressed Boiler Steel Subject to Corrosion by Alkaline Solution 16 . Note Honeycomb of Fine Cracks Which Do Not Cut Across Grains of the Metal But Follow the Grain Boundaries. 
A paper by Schmidt, Gegner, Heinemann, Pogacar, and Wyche, 17 reports on the results of a survey involving a large number of actual applications of metals in service handling caustic solutions. Figure 11 is a plot of the data obtained for mild steel. Regions of concentration and temperature above the curve in this figure represents areas where cracking is likely to occur.

Berk and Waldeck, in a comprehensive paper 18 describe the results of embrittlement tests with caustic solutions, and give what they call a "caustic danger zone" on a temperature-concentration plot, above which failure is likely to.occur. They used stressed mild steel specimens with test durations varying from six to sixty-two days. Their data are reproduced in Figure 12. It is of interest to note that the "caustic danger zone" is located at a higher temperature than the "Iimiting temperature curve" as given by schmidt et.al. (see Figure 11), indicating that the latter curve may be conservative. On the other hand, it is significant that the laboratory tests were run for a maximum of only sixty-two days, whereas the field data include reference to cases of many years of service.

An article by Fontana ${ }^{19}$ presents an excellent discussion on the action of materials of construction. He states that generally the caustic corrosion resistance of a material is almost proportional to the nickel content. The chief metals and alloys used for caustic services, listed roughly in order of corrosion resistance, are given as follows: Inconel, Monel, cupronickel, austenitic stainless steel and alloys, austenitic cast iron such as Ni-Resist, 9\% nickel steel, low nickel alloy cast irons and steels, and ordinary steel and cast iron. Thus AISI 300 series stainless steel ranks considerably above carbon steel in its resistance to possible caustic attack. Four factors are listed as being significantly involved in the tendency for caustic cracking in steel. These are caustic concentration, temperature, exposure time, and stress.

Only two examples of caustic cracking of austenitic stainless steel were located in this survey. These are reported by Gallbourg 20 and by Edeleanu-Snowden, 21 In the former case the occurrence of alkaline embrittlement is reputed. to have produced cracks in $22 \%$ nickel, $2 \%$ chromium steel in the presence of superheated steam. The latter work describes a case in which caustic cracking was observed in austenitic stainless steel after sample specimens were coated by being dipped in molten caustic and then exposed to highly superheated steam $\left(310^{\circ} \mathrm{C}\right.$, $150 \mathrm{lb} / \mathrm{in}^{2}$ ). Needless to say, these conditions are significantly more rigorous than any to be anticipated in a reactor decontamination operation using the basic permanganate procedure. 


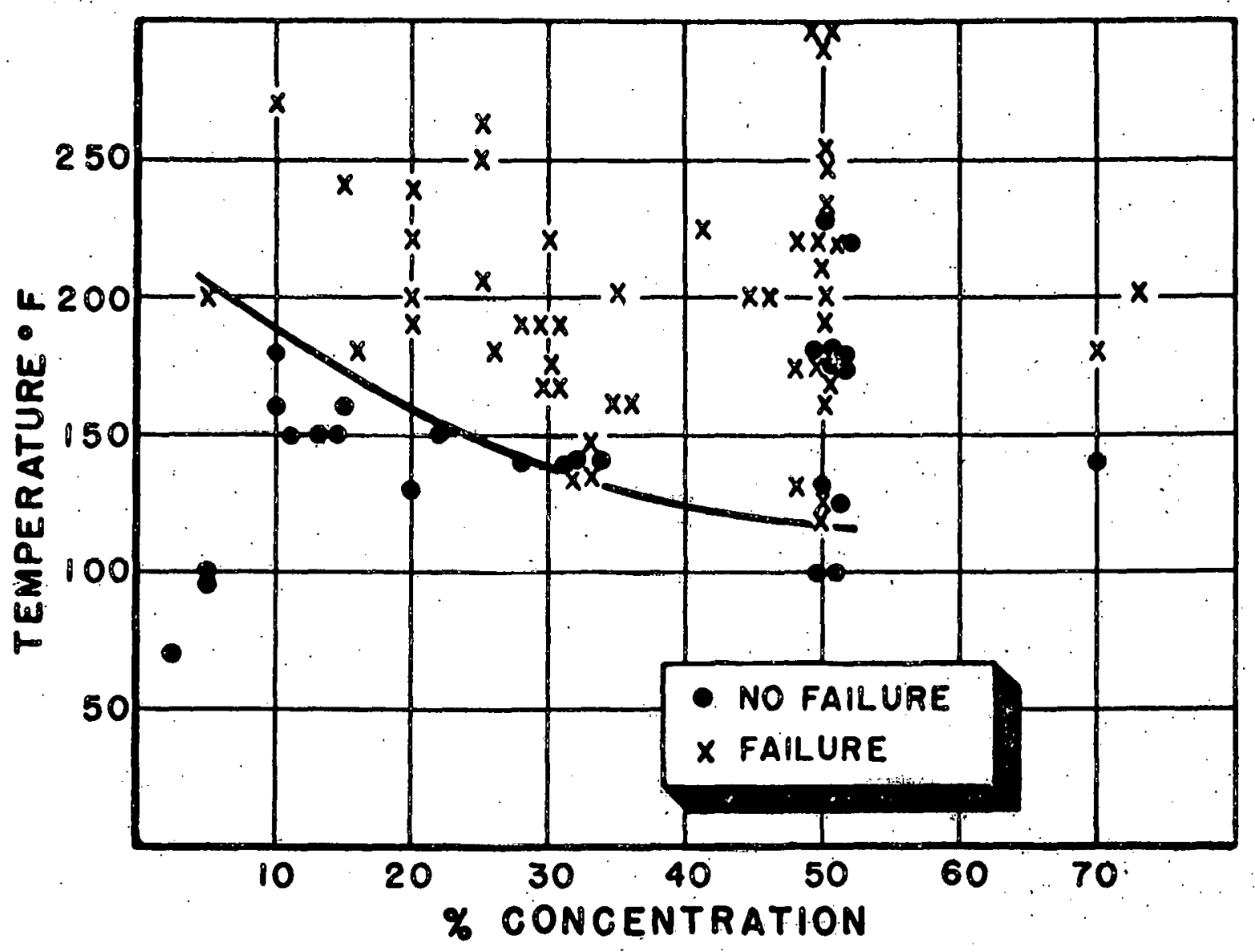

Figure 11 Effects of Temperature and Concentration on Cracking of Mild Steel in Sodium Hydroxide (Based on Actual

Service Experience and Reported in a Paper by Schmidt et al! ). 


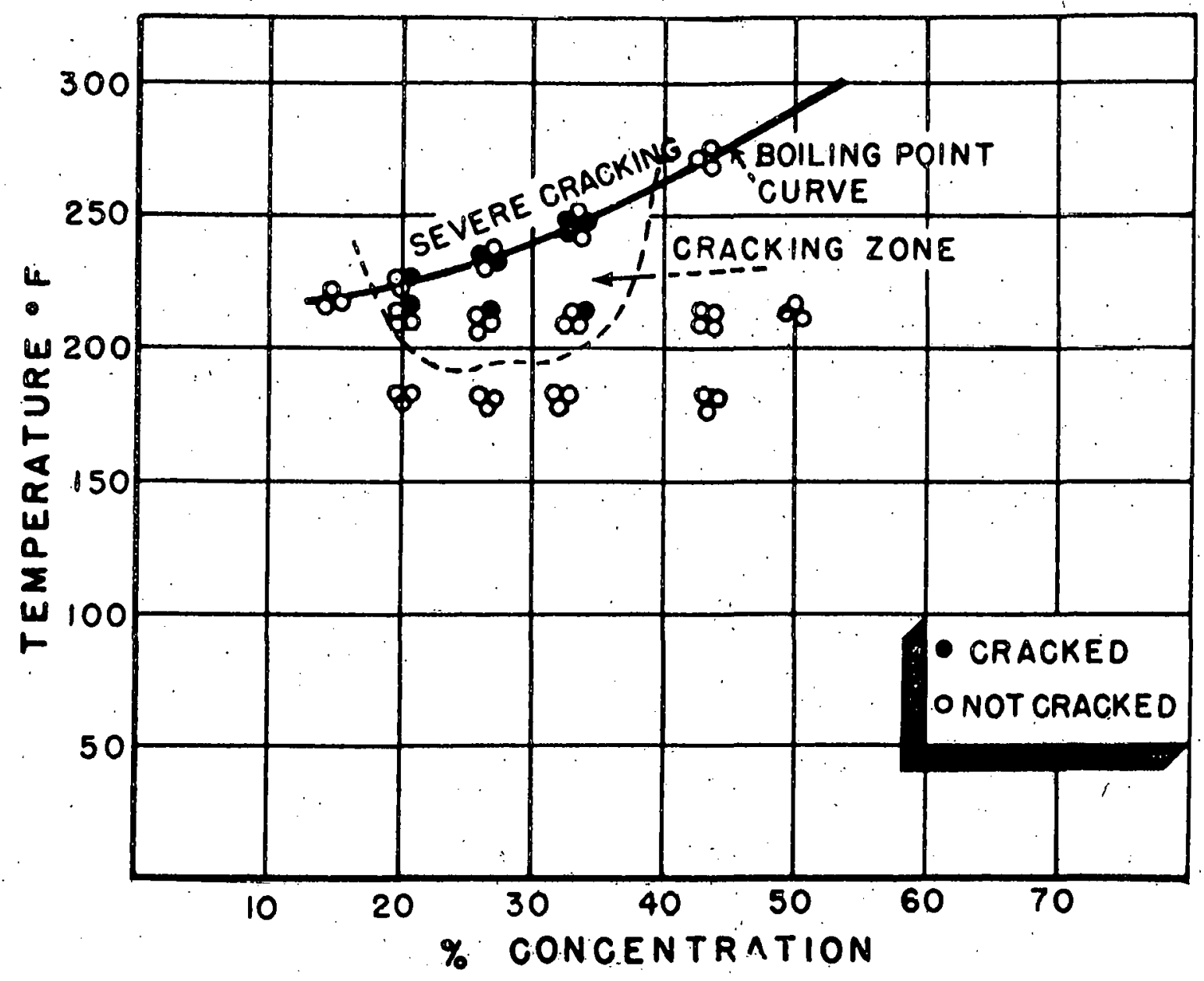

Figure 12 Caustic Danger Zone Resulting From the Use of Caustic Solutions on Mild Steel Specimens as Reported by Berk and Waldeck ${ }^{6}$. 


\section{B. IABORATORY EVALUATION}

1. Fatigue Tests.- Standard 1/8 inch thick specimens of AISI 304 stainless steel were prepared and fatigue tested on a. Sonntag testing machine model SF-.LOU. Two series of experiments were performed, each with a different loading in order to modify the breaking point of the specimens. The "pretreated specimens" were exposed for 20 hours to a $20 \% \mathrm{NaOH}, 3 \% \mathrm{KMnO}_{4}$ solution at $105^{\circ} \mathrm{C}$ prior to testing. As illustrated in Figure 13, the results obtained in the two test series varied widely and no significant relationshir. was apparent between break point and whether or not the specimen had been pretreated with the basic permanganate solution (see Figure 14).

2. Cold Bend Test.- A series of cold bend tests was performed on specimens of pretreated and untreated AISI 304 stainless steel in an effort to determine whether or not the exposure to the basic permanganate solution has produced embrittlement of the metal. One specimen which had originally been prepared for fatigue testing (see previous section) was pretreated for 20 hours as before. Another was exposed for 48 hours to a $70 \%$ solution of $\mathrm{NaOH}$ maintained at approximately $150^{\circ} \mathrm{C}$, while a third specimen was used as a control. All three were bent $180^{\circ}$ using a 2 inch diameter pipe as a guide. (This pipe diameter was equal to twice the width of the specimens at the point of bending.) Examination of the bend areas of the three specimens under $1.5 \mathrm{X}$ magnification did not reveal signs of caustic cracking. (See Figure 15 and 16.)

3. Metallographic Examination.-.. After microscopic examination, the cold bend test specimens were sectioned, mounted, polished, and etched prior to remexamination under $400 \mathrm{X}$ magnification (see Figure 17). There appeared to be little or no difference between the structure of the control "blank" and the sample pretreated for 20 hours with the basic permanganate reagent. No slgnificant attack had taken place. The specimen that was subject to the most rigorous treatment ( 48 hours contact with $70 \% \mathrm{NaOH}$ at $150^{\circ} \mathrm{C}$ ) appeared to have suffered slight intergranular attack. Even in this case, however, the maximum depth of grain boundary penetrations seemed negligible (less than $0.5 \mathrm{mil}$ ), and there was no evidence of "caustic cracking" or embrittlement. (See Figures 17, 18, and 19.)

\section{FUTURE OUTLOOK}

With the completion of this first phase of the Yankee Research and Development Program Decontamination Project the foundation has been laid for future large scale testing of the selected decontamination procedure. In an attempt to gain experience with the application of the basic permanganate-citrate procedure in situations more closely approaching the actual reactor 

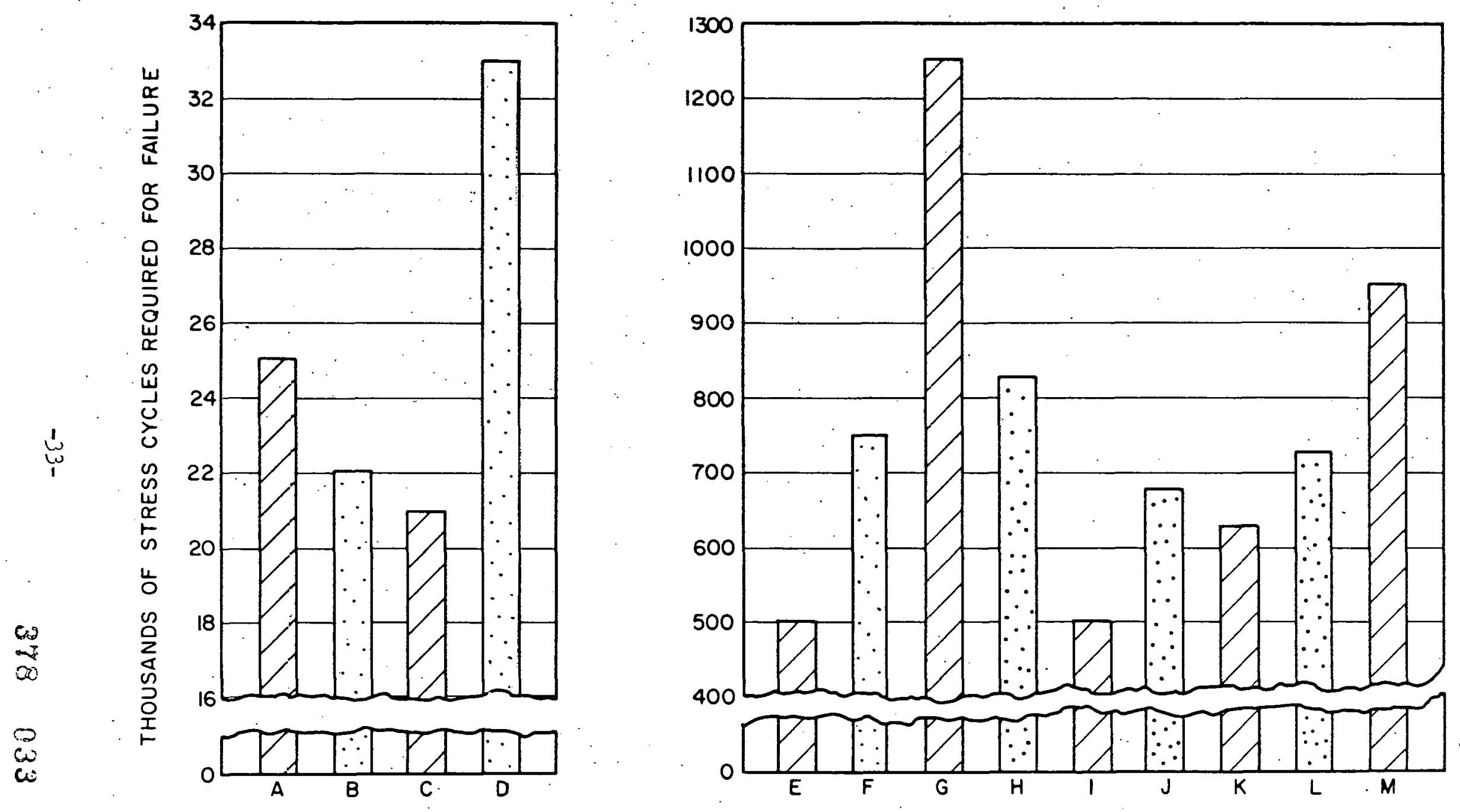

SPECIMEN DESIGNATIONS, PRETREATED $Z$, UNTREATED $\cdots$

AISI 30,4 STAINLESS STEEL FATIGUE TEST RESULTS

FIGURE 13 


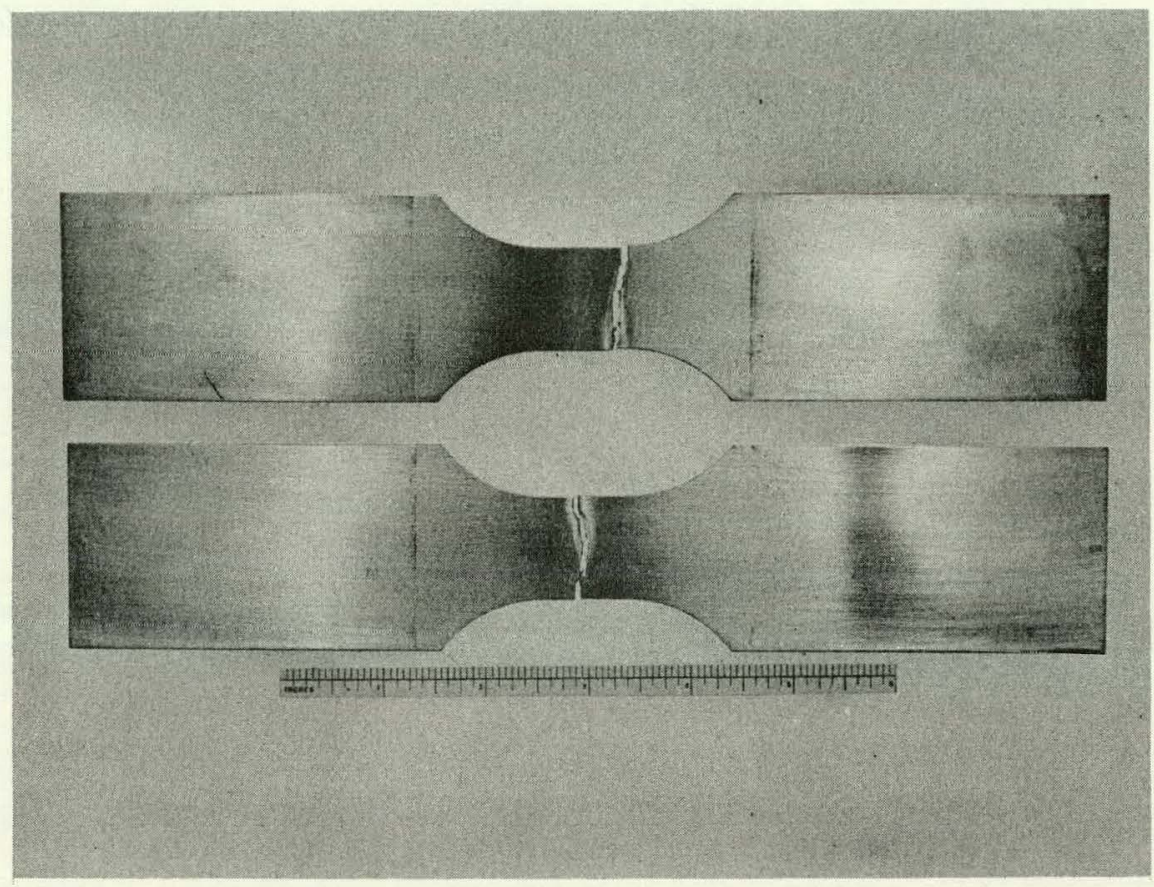

Figure 14 AISI 304 Stainless Steel Fatigue Test Specimens after Failure. Top Untreated, Bottom Pretreated with the Basic Permanganate Decontarnination Reagent. 


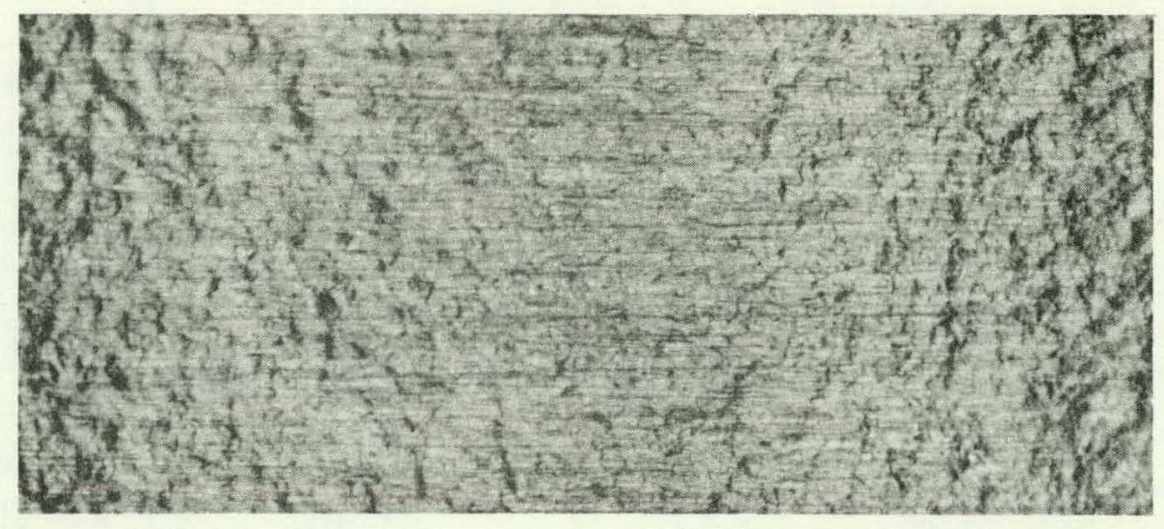

(a)

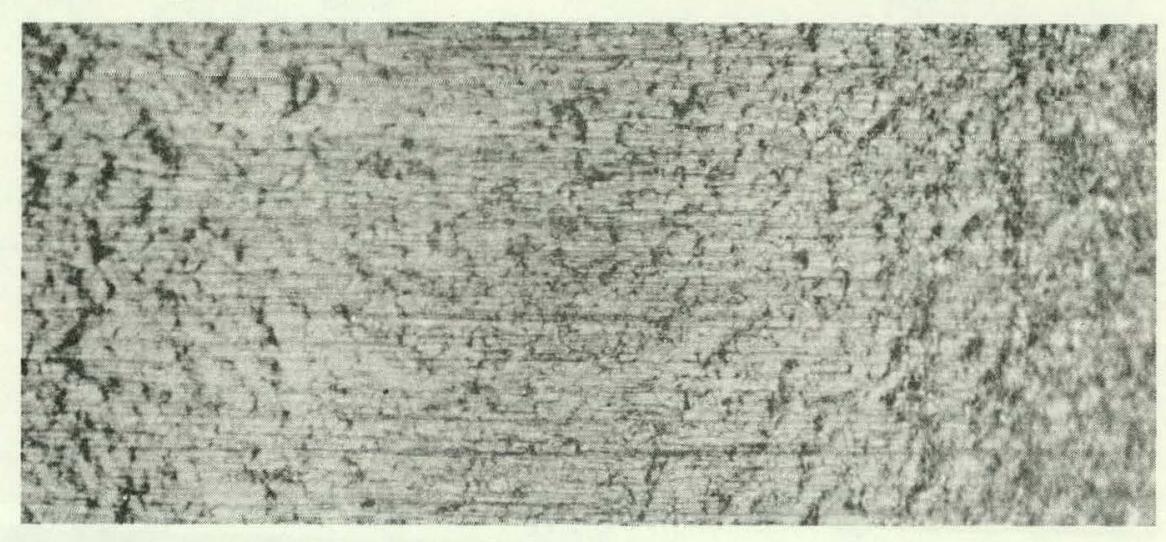

(b)

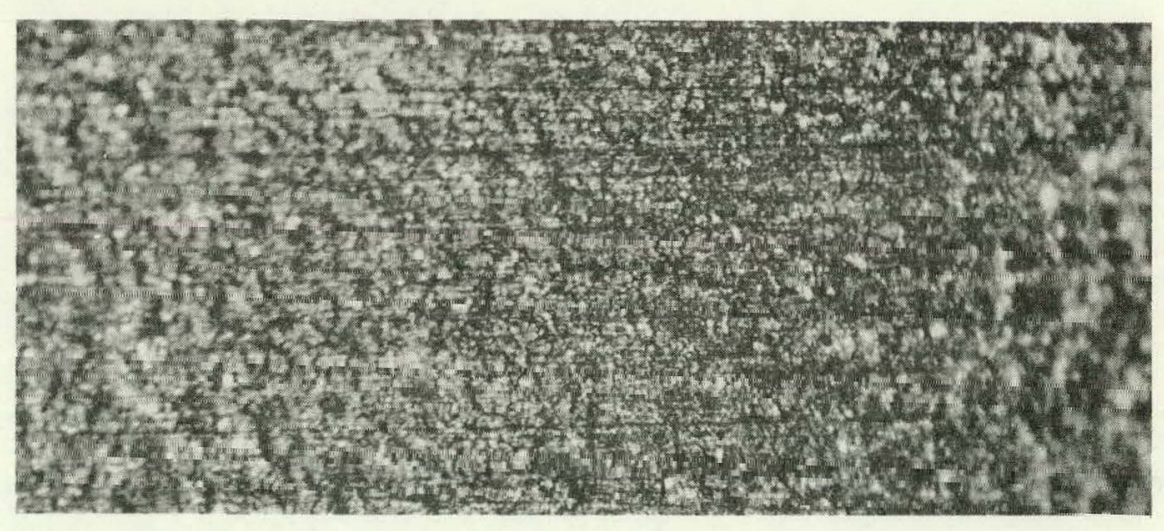

(c)

Figure 15 Bend Area Surface of AISI 304 Stainless Steel Cold Bend Test Specimens 30x, (a) Untreated, (b) Pretreated 20 Hours With Basic Permanganate Reagent at $105^{\circ} \mathrm{C}$, (c) Pretreated 48 Hours With $70 \% \mathrm{NaOH}$ at $150^{\circ} \mathrm{C}$. 


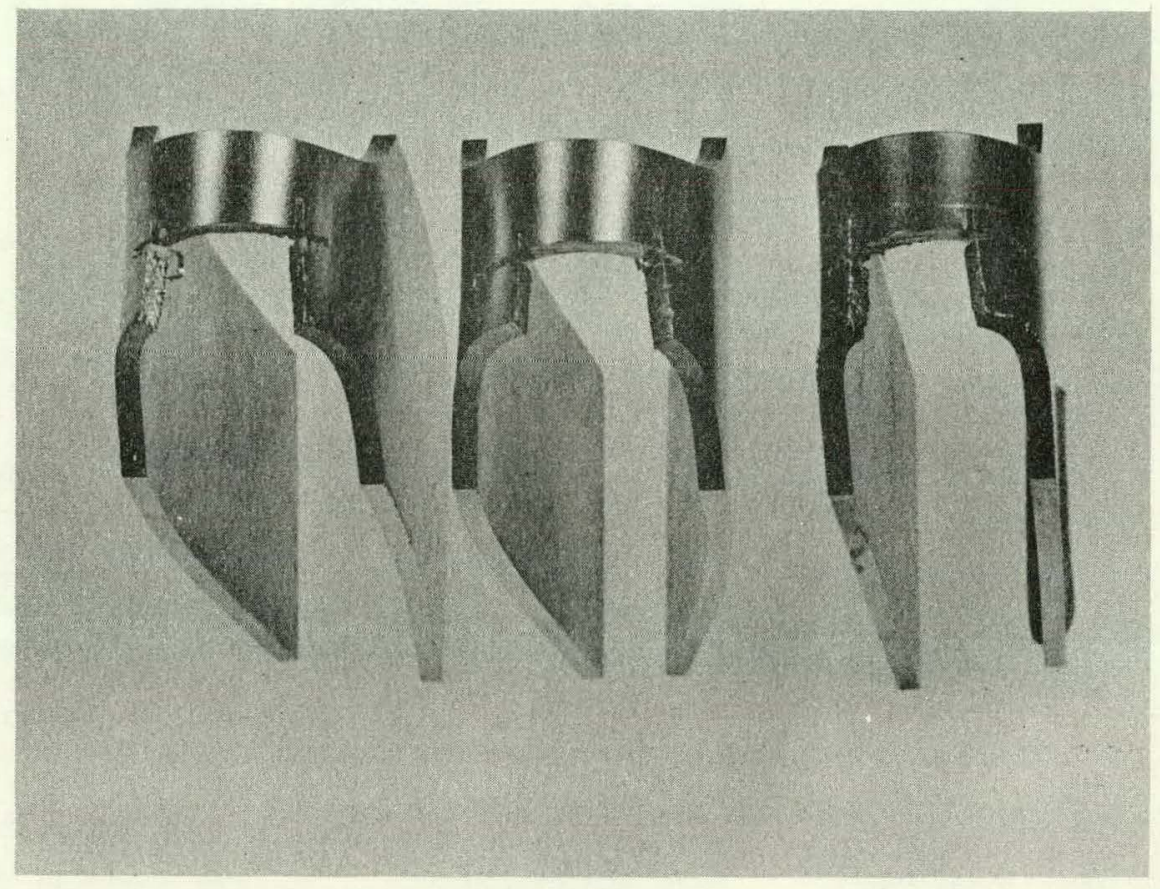

Figure 16 Cold Bend Test Specimens of AISI 304 Stainless Steel Showing Sections Removed for Metallographic Analysis. Left to Right, Untreated, Pretreated 20 Hours With Basic Permanganate Reagent at $105^{\circ} \mathrm{C}$, Pretreated 48 Hours With $70 \% \mathrm{NaOH}$ at $150^{\circ} \mathrm{C}$. 


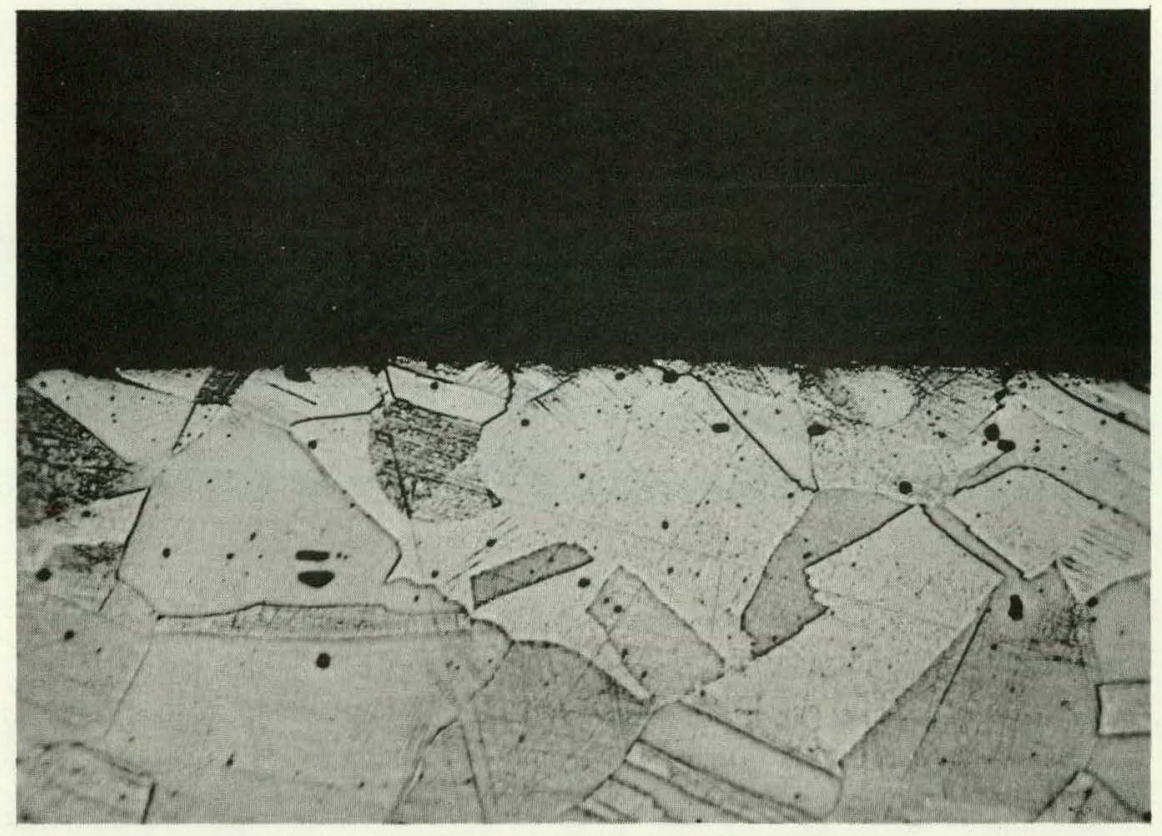

(a)

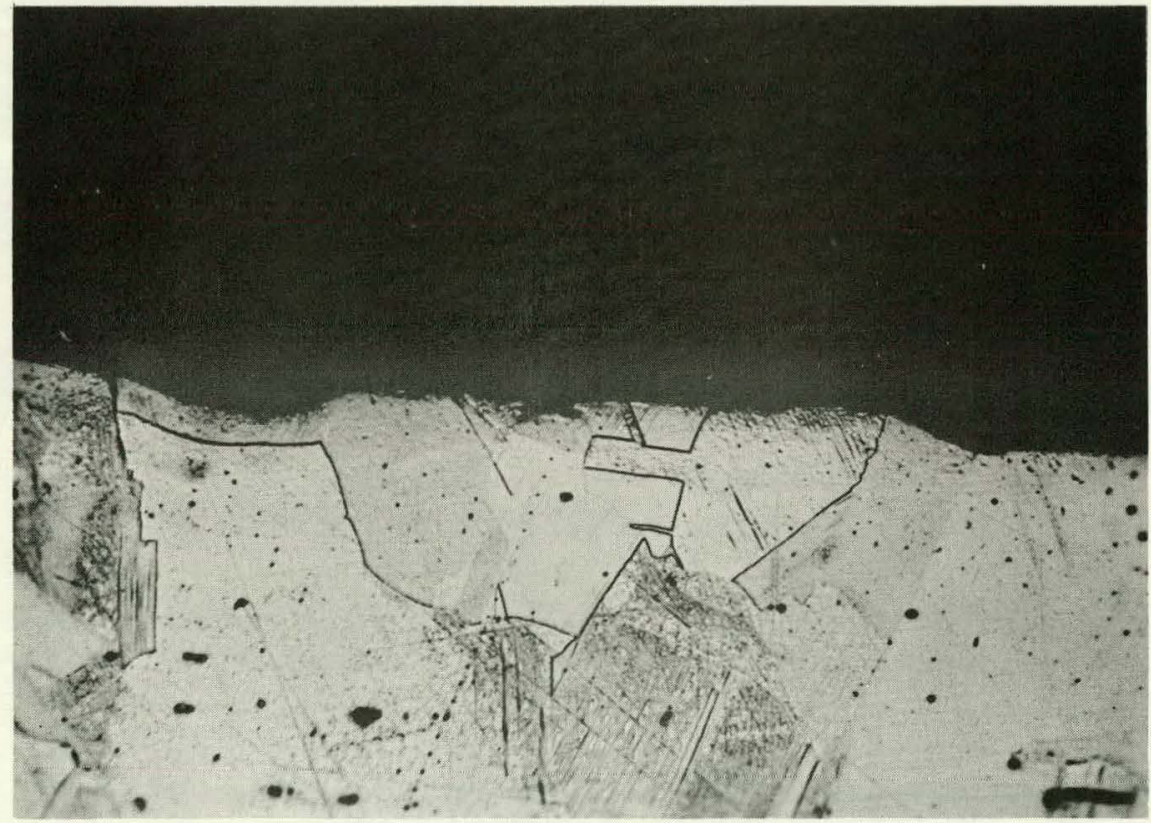

(b)

Figure 17 Photomicrographs (400X) of Edge of AISI 304 Stainless Steel Cold Bend Test Specimen, Pretreated for 20 Hours at $100^{\circ} \mathrm{C}$ to the Basic Permanganate Decontamination Reagent. (a) Outside of Bend, (b) Inside of Bend. 


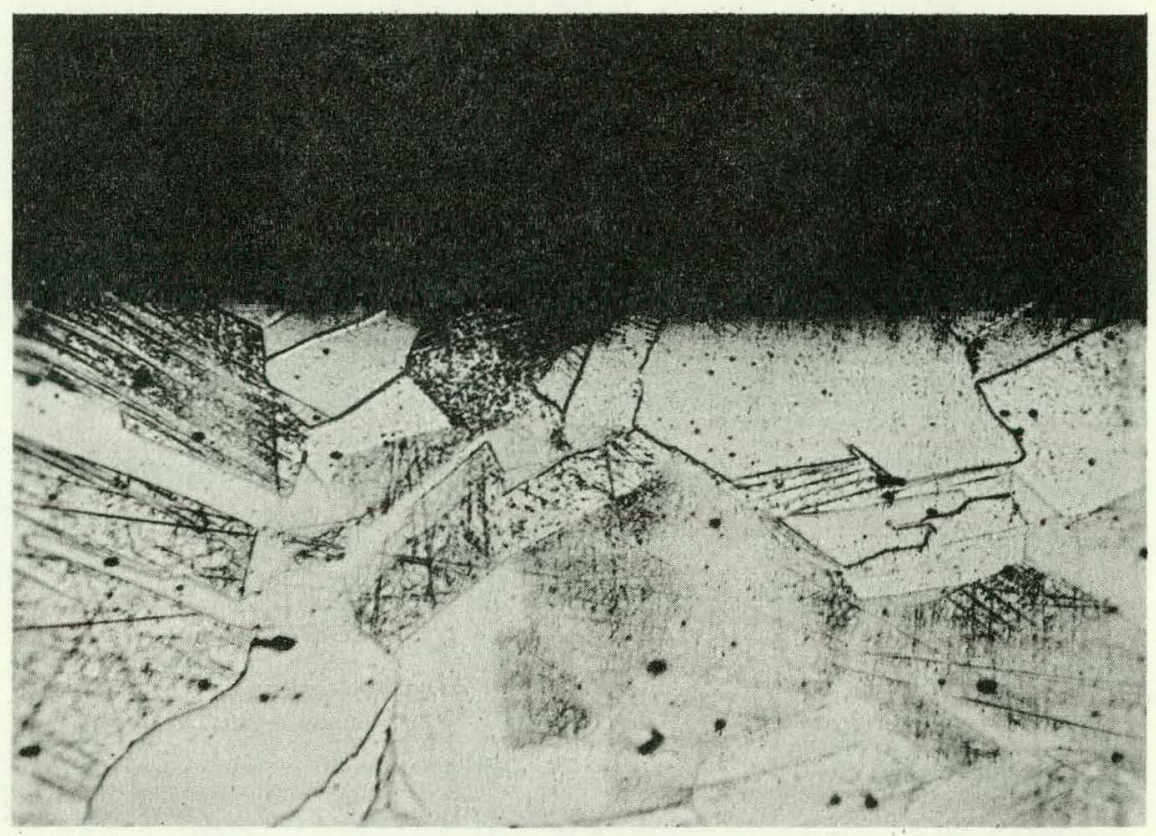

(a)

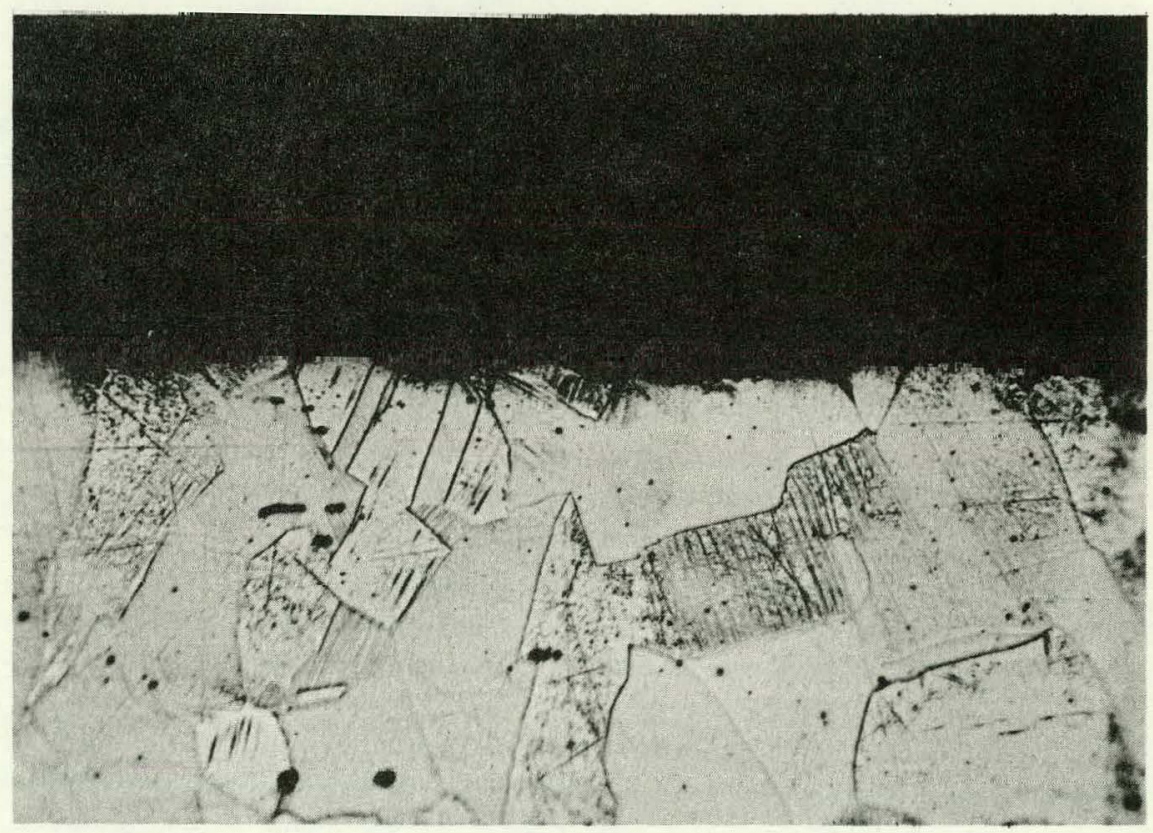

(b)

Figure 18 Photomicrographs (400X) of Edge of AISI 304 Stainless Steel Cold Bend Test Specimen, Pretreated for 48 Hours at $150^{\circ} \mathrm{C}$ with $70 \% \mathrm{NaOH}$. (a) Outside of Bend, (b) Inside of Bend. 


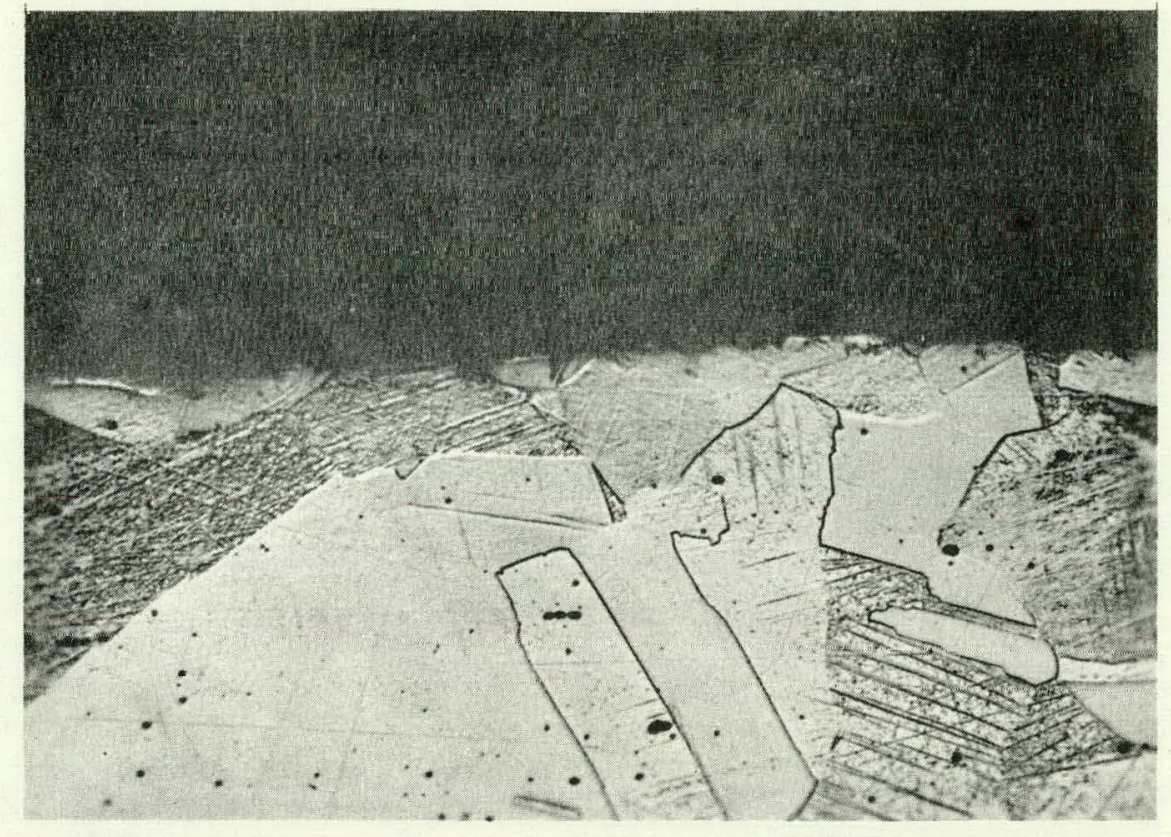

(a)

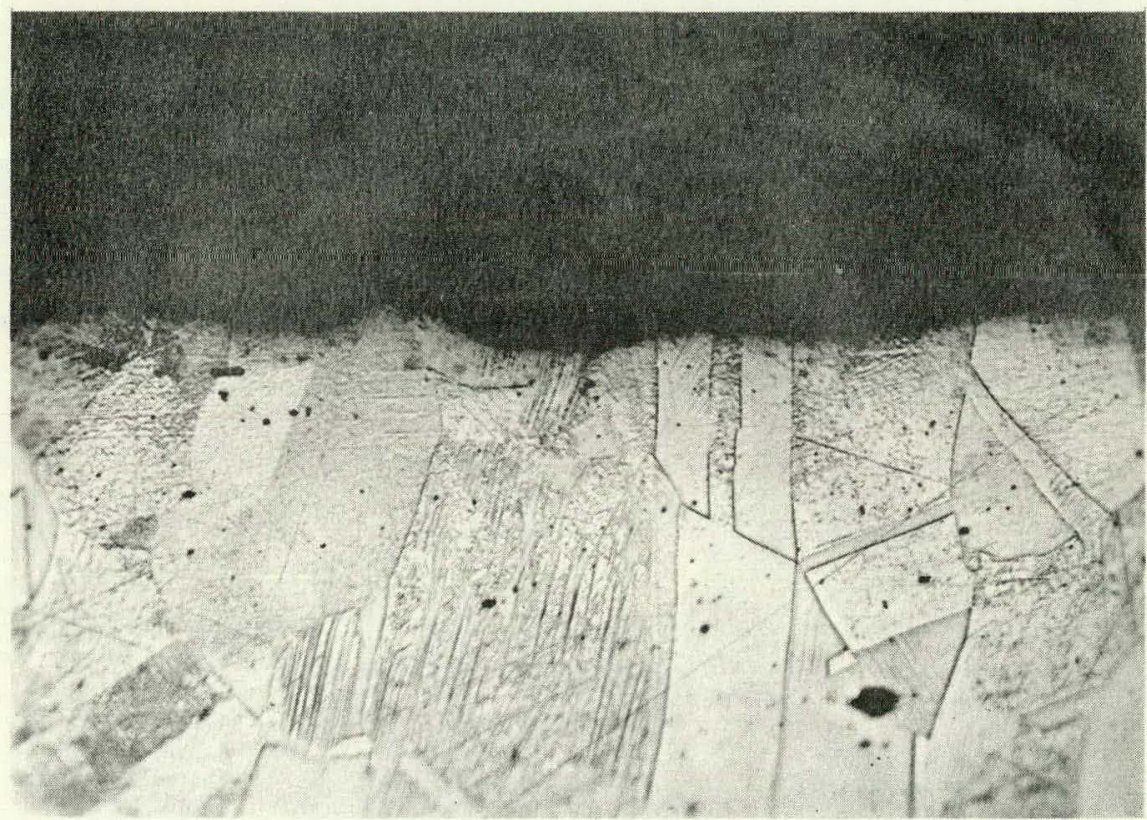

(b)

Figure 19 Photomicrographs (400X) of Edge of AISI 304 Stainless Steel Cold Bend Test Specimen Blank - Not Exposed to Basic Permanganate Reagent. (a) Outside of Bend, (b) Inside of Bend. 
application, dynamic autoclave system cleanup trials and large loop decontamination tests will be conducted. This procedure, which has proven to be effective in small "bench scale" experimentation will be refined to the point where 15 gallon batches of the reagents may be handled easily and employed efficiently in the cleanup of circulating systems.

It has been proposed that the second phase of the Decontamination Project be concluded with the cleanup of the Yankee In-Pile Test Loop at the MTR site. This could be performed at the completion of the Yankee fuel element irradiation damage test program. The opportunity to conduct a cleanup of this contaminated system (which will have been operated for 12 months under conditions of water chemistry and neutron flux approaching as closely as possible those anticipated for the actual primary coolant system), would offer additional evidence as to the feasibility of applying the basic permanganate-c1trate procedure in actual Yankee reactor system decontamination. The quantitative decontamination factors obtained in this test would be extremely valuable in estimating the degree of cleanup to be achieved in actual plant usage of this method and would provide practical proof of the effectiveness of the procedure.

The third and final phase of the Decontamination Project will involve an organization of all information known concerning the state of the cleanup art as it pertains to the Yankee plant, and the writing of a detailed "Decontamination Giide" for the application of the selected chemical procedure in actual primary coolant system decontamination. 


\section{ACKNOWLEDGEMENT}

The author wishes to express his appreciation to Mr. R. F. Sterling, Manager of the Chemistry and Ceramics Section, Nuclear Core Engineering Group of the Westinghouse Atomic Power Department for his valued advice and helpful suggestions during the course of this work. Thanks is also paid to Mrs. D. J. Rahn of the Technical Service Laboratories, Westinghouse Atomic Power Department for her cooperation in the performance of the metallographic examinations of specimens mentioned in this report. 
1. ORNL-1826 (Decl)

Campbell D. O., Decontamination of Stainless Steel

March 2, 1955 Decl. with deletions Feb. 22, 1957.

2. $\mathrm{HW}-46369$

Walker W. L., The Corrosion of Type $304 \mathrm{~L}$. Stainless Steel by Solutions of Nitric Acid - Sodium Diç'tromate and Nitric Hydrofluoric Acids. October 29, 1956.

3. WAPD-PWR-CP-2079

Droll H. A., High Temperature Stability of Aqueous Solution of Reagents that are Potentially Applicatory to PWR Decontamination Process.

4. WAPD-PWR-CP-2719

Proposed Procedures for Chemical Decontamination of PWR. 157

5. WAPD-CDA (AD) -34, Outline of Proposed Bettis Decontamination Procedure.

6. WAPD-CDA (AD) -48

Loyd, $R_{0}$, and Lindsay, W. To, Decontamination of the WAPD-29 Loop.

7. APAE-25

Medin, A. L., Literature Survey for Activity Build-up on Reactor Primary System Components.

8. KAPL-M-SMS-48,

Steiner, F. C., Procedure for Decontamination of Primary Coolant Systems, 156.

9. Baybarz, R. D., Decontamination of a Homogeneous Reactor ORNL Central File No. 57-9-59, (Presented at American Nuclear Society Meeting, Pittsburgh, $\mathrm{Pa}_{0}$, June 10-12, 1957)。

10. N1sersưn, S. $M_{0}$, and DeBolt, $H_{0} F_{i}$, Decontamination of Nuclear Reactor Control Rod Drive Mechanisms (Presented at the Fourth National Annual Meeting of the Professional Group on Nuclear Science of the IRE).

11. Nisenson, S, Mo, Personal Communication.

12. United States Steel Corporation - Fabrication of USS Stainless Steel, Second Edition, 1956, Page 88.

13. HW-34811

Cortlett R. F., and Kolb J.W., Investigation of ULtrasonic Decontamination. Jan. 28, 1955 
14. 5AECU-3590, Henry G. E., UItrasonics for Radioactive Decontamination. .Nov. 14, 1957.

15. YAEC-68. (to be issued)

Krieg, A., Eaton, G. A., and Garretson, R. C., Corrosion of AISI Type 304 Stainless Steel in High Temperature Boronated Water.

16. Uhlig H. H., Corrosion Handbook, John Wiley and Sons, New York, (1955).

17. Schmidt H. W., Gregner J. P., Heinemann G., Pogacar C. F., and Wyche E. H., Stress Corrosion Cracking in Alkaline Solutions, Corrosion, 7, 295, (1951).

18. Berk A. A., and Waldeck W. F., Caustic Danger Zone, Chemical Engineering, 57, No. 6, 235-237 (1950) June.

19. Fontana M. G., Materials of Construction for Handling Caustic, Industrial and Engineering Chemistry, 44, 81A, (1952) June.

20. Galibourg J., Mechanical Properties and Corrosion of Steel, Chemie et Industrie, 47, Speciial Number 168-178 (1939).

21. Edeleanu C., and Snowden P. P., Stress Corrosion of Austenitic Stainless Steels in Steam and Hot-Water Systems, Journal of the Iron and Steel Institute, August, 1957.

22. Instruction Manual, Sonntag Fatigue Testing Machine Model SF-I-U, Baldwin-Lima-Hamilton Corp. Electronics and Instrument Division, Waltham, Massachusetts. 